\title{
Critical values for unit root tests in seasonal time series
}

PHILIP HANS FRANSES \& BART HOBIJN, Econometric Institute, Erasmus University Rotterdam, The Netherlands

SUMMARY In this paper, we present tables with critical values for a variety of tests for seasonal and non-seasonal unit roots in seasonal time series. We consider (extensions of) the Hylleberg et al. and Osborn et al. test procedures. These extensions concern time series with increasing seasonal variation and time series with structural breaks in the seasonal means. For each case, we give the appropriate auxiliary test regression, the test statistics, and the corresponding critical values for a selected set of sample sizes. We also illustrate the practical use of the auxiliary regressions for quarterly new car sales in the Netherlands. Supplementary to this paper, we provide Gauss programs with which one can generate critical values for particular seasonal frequencies and sample sizes.

\section{Introduction}

Testing for unit roots in economic time series has become standard practice in many applications. The key focus of such tests is that the practitioner wishes to decide whether a time series is generated by a stochastic trend process, i.e. a process where shocks have a permanent effect, or a stationary time series, where shocks only have a temporary effect. An example of the first type of process is the simple random walk $y_{t}=y_{t-1}+\varepsilon_{t}$, which can be written as

$$
y_{t}=y_{0}+\sum_{i=0}^{t-1} \varepsilon_{t-i}
$$

This expression clearly shows that the effect of shocks $\varepsilon_{i}$ does not die out as

Correspondence: Philip Hans Franses, Econometric Institute, Erasmus University Rotterdam, PO Box 1738, NL-3000 DR Rotterdam, The Netherlands.

This paper is a revision and extension of Franses (1990). The programs to generate the critical values are written in Gauss $386 \mathrm{i}$ and can be obtained via e-mail, by sending a request to franses@few.eur.nl. The four programs correspond to Sections $2-5$ in this paper. 
time proceeds. This is in contrast to the stationary first-order autoregression $y_{t}=\rho y_{t-1}+\varepsilon_{t}$, with $|\rho|<1$, which can be written as

$$
y_{t}=\rho^{t} y_{0}+\sum_{i=0}^{t-1} \rho^{i} \varepsilon_{t-i}
$$

A test procedure to select between these two data representations, which is often used in practice, is based on regressions as $y_{t}-y_{t-1}=\pi y_{t-1}+\psi_{t}$, where $\psi_{t}$ is some error process. This regression is often called the Dickey-Fuller (DF) regression (Dickey \& Fuller, 1979), and the DF test concerns the $t$-ratio of $\pi$. When $\pi=0$, one opts for the stochastic trend process, and when $\pi<0$, the process is said to be stationary. Since the study of Dickey and Fuller (1979), a vast amount of literature has emerged on the theoretical and practical properties of unit root tests. An overview of this literature is beyond the scope of this paper, but the interested reader may consult Banerjee et al. (1993) and the references cited therein, for example.

In this paper, we focus on testing for unit roots in seasonal time series. We present tables with critical values for several tests for seasonal and non-seasonal unit roots in seasonal time series. In each of the sections in this paper, we give details of the auxiliary test regression, the appropriate test statistic(s) and a selected set of critical values. Additional tables can be generated using the Gauss $386 i$ programs that accompany this paper. We limit ourselves to displaying the critical values, so we do not provide any details on the asymptotic distributions, other than whether these can be found in the literature or whether these have to be derived in subsequent research. All auxiliary regressions are illustrated using the quarterly time series of new car sales in the Netherlands. The data are given in the appendix to facilitate replication of the empirical results.

The outline of this paper is as follows. In Section 2, we discuss tests for seasonal and non-seasonal unit roots based on the method which is proposed in Hylleberg et al. (1990). We consider biannual, quarterly, bimonthly and monthly time series. In Section 3, we consider an extension of the method of Hylleberg et al. (1990) which considers all seasonal unit roots at the same time, which is slightly different from the method proposed by Ghysels et al. (1994). This extension can be useful for seasonal time series where the seasonal frequency is 5 or 13 and, hence, where separate seasonal unit roots may be less useful in practice. This extension bears similarities to the method of Osborn et al. (1988). In Section 4, we consider the method of Osborn et al., which is often used in case one wants to allow for the presence of two non-seasonal unit roots. Because more than one non-seasonal unit root and multiple seasonal unit roots may appear in time series with increasing seasonal variation, we extend the method of Osborn et al. to become useful in such occasions. Finally, in Section 5, we consider the method of Hylleberg et al. (1990) in the case where one allows for one known structural break in the seasonal means in the auxiliary regression. This can be useful, because such a break may bias a test for seasonal unit roots towards non-rejection, so one may too often find seasonal unit roots.

First, however, we make a few remarks on notation. We denote the time series of interest as $y_{t}$, where $t=1, \ldots, n$; this series is observed for $S$ seasons, where $S$ can be $2,4,6$ or 12 , but sometimes also 5 or 13 . We denote a standard white noise process as $\varepsilon_{t}$, which is a zero-mean uncorrelated process with constant variance of $\sigma^{2}$. The familiar backward shift operator $B$ is defined by $B^{k} y_{t}=y_{t-k}$, where $k=1,2, \ldots$, and the differencing filter $\Delta_{k}$ is defined by $\Delta_{k} y_{t}=y_{t}-y_{t-k}$. In this 
paper, we assume that $y_{t}$ can be approximately described by an autoregressive process of order $p(\operatorname{AR}(p))$, i.e.

$$
\phi_{p}(B) y_{t}=\mu_{t}+\varepsilon_{t}
$$

where $\phi_{p}(B)$ is defined by

$$
\phi_{p}(B)=1-\phi_{1} B-\phi_{2} B^{2}-\ldots-\phi_{p} B^{p}
$$

and where $\mu_{t}$ can contain a variety of deterministic terms. In this paper, we assume that the deterministic terms are at most

$$
\mu_{t}=\alpha_{0}+\sum_{s=1}^{s-1} \alpha_{s} D_{s t}+\beta_{0} t+\sum_{s=1}^{s-1} \beta_{s} D_{s t} t
$$

where $t$ is a deterministic trend variable, $t=1,2,3, \ldots$, and the $D_{s t}$ terms are seasonal dummy variables which take a value of 1 in season $s$ and 0 elsewhere. The terms $\alpha_{i}$ and $\beta_{i}, i=0,1, \ldots, S-1$, are unknown parameters.

The main focus in the present paper is to investigate if the solutions of equation (2) are on the unit circle. For example, in Section 2, we investigate whether or not $\phi_{p}(B)$ can be decomposed as $\phi_{p-s}(B)\left(1-B^{S}\right)$, while we check in Section 4 if it can be decomposed as $\phi_{p-\left(S_{+}\right)}(B)\left(1-B^{S}\right)(1-B)$.

\section{Non-seasonal and seasonal unit roots}

The assumption of a certain differencing filter amounts to an assumption on the number of seasonal and non-seasonal unit roots in a time series. This can easily be understood by writing $\Delta_{S}=\left(1-B^{S}\right)$, and by solving the equation

$$
\left(1-z^{S}\right)=0
$$

or

$$
\exp (\operatorname{Si} \phi)=1
$$

for $z$ or $\phi$, where $\mathrm{i}$ is the complex number such that $\mathrm{i}^{2}=-1$. The general solution to equation (5) is $\{1, \cos (2 \pi k / S)+\mathrm{i} \sin (2 \pi k / S)\}$ for $k=1,2, \ldots$, yielding $S$ different solutions to equations (4) and (5), which all lie on the unit circle.

For example, in the case of $S=4$, the solutions to $\left(1-z^{4}\right)=0$ are $\{1, \mathrm{i},-1,-\mathrm{i}\}$. This means that, for this case, we can write

$$
\begin{aligned}
\Delta_{4}=\left(1-B^{4}\right) & =(1-B)(1+B)(1-\mathrm{i} B)(1+\mathrm{i} B) \\
& =(1-B)(1+B)\left(1+B^{2}\right) \\
& =(1-B)\left(1+B+B^{2}+B^{3}\right)
\end{aligned}
$$

The unit root 1 is called the non-seasonal unit root, while the unit roots -1 and $\pm \mathrm{i}$ are called the seasonal unit roots (see, for example, Hylleberg et al., 1990). Any differencing filter $\Delta_{S}$ can be written as $\Delta_{S}=(1-B)\left(1+B+\ldots+B^{S-1}\right)$, so that any $\Delta_{S}$ can be decomposed into a part with one non-seasonal unit root and a part with $S-1$ seasonal unit roots.

Hylleberg et al. (1990) propose a method to test for the presence of seasonal and non-seasonal unit roots in quarterly time series. Their method is based on the auxiliary regression

$$
\phi(B) y_{4, t}=\mu_{t}+\pi_{1} y_{1, t-1}+\pi_{2} y_{2, t-1}+\pi_{3} y_{3, t-2}+\pi_{4} y_{3, t-1}+\varepsilon_{t}
$$


where $\phi(B)$ is an AR polynomial of order $p-4$, where $\mu_{t}$ is at most

$$
\mu_{t}=\alpha_{0}+\sum_{s=1}^{3} \alpha_{s} D_{s t}+\beta_{0} t
$$

and where

$$
\begin{aligned}
& y_{4, t}=\left(1-B^{4}\right) y_{t} \\
& y_{1, t}=\left(1+B+B^{2}+B^{3}\right) y_{t} \\
& y_{2, t}=-(1-B)\left(1+B^{2}\right) y_{t} \\
& y_{3, t}=-\left(1-B^{2}\right) y_{t}
\end{aligned}
$$

An application of the ordinary least squares (OLS) method to equation (7), where the order of $\phi(B)$ is usually determined using diagnostic checks such that the estimated process $\hat{\varepsilon}_{t}$ is approximately white noise, yields estimates of $\pi_{1}, \pi_{2}, \pi_{3}$ and $\pi_{4}$.

In Hylleberg et al. (1990), it is shown that certain $\pi_{j}$ terms are zero in the case where corresponding roots are on the unit circle. Hence, testing for the significance of the $\pi_{j}$ terms implies testing for seasonal and non-seasonal unit roots. There are no seasonal unit roots when $\pi_{2}, \pi_{3}$ and $\pi_{4}$ are different from zero. If $\pi_{1}=0$, then the presence of the non-seasonal unit root 1 cannot be rejected. If $\pi_{2}=0$, then the seasonal unit root -1 cannot be rejected. If $\pi_{3}=\pi_{4}=0$, then one cannot reject the seasonal unit roots $\pm \mathrm{i}$. The various hypotheses can be tested using (one-sided) $t$-tests for $\pi_{1}$ and $\pi_{2}$, and a joint $F$-test for $\left\{\pi_{3}, \pi_{4}\right\}$. Note that Hylleberg et al. (1990) also propose two $t$-type tests for $\pi_{3}$ and $\pi_{4}$ but, for the sake of convenience, these are not used here. Ghysels et al. (1994) extend the work of Hylleberg et al. (1990) by proposing $F$-tests for the joint significance of $\left\{\pi_{1}, \pi_{2}, \pi_{3}, \pi_{4}\right\}$ and of $\left\{\pi_{2}, \pi_{3}, \pi_{4}\right\}$.

Before we turn to displaying the critical values for the test statistics mentioned above, we give auxiliary regressions similar to equation (7) for biannual, bimonthly and monthly time series. Derivations of these bimonthly and monthly regressions can be found in Franses (1991a,b) (see also Beaulieu and Miron (1993) for monthly time series). For biannual data, $S=2$, so $\Delta_{2}$ can simply be decomposed as $(1-B)(1+B)$, and the auxiliary regression is

$$
\phi(B) y_{3, t}=\mu_{t}+\pi_{1} y_{1, t-1}+\pi_{2} y_{2, t-1}+\varepsilon_{t}
$$

where $\phi(B)$ is an $\operatorname{AR}(p-2)$ polynomial, where

$$
\begin{aligned}
& y_{3, t}=\left(1-B^{2}\right) y_{t} \\
& y_{1, t}=(1+B) y_{t} \\
& y_{2, t}=-(1-B) y_{t}
\end{aligned}
$$

and where $\mu_{t}$ is at most similar to equation (8). For biannual time series, we consider the $t$-tests for $\pi_{1}$ and $\pi_{2}$, which correspond to the $(1-B)$ and $(1+B)$ filters respectively. Furthermore, we consider the $F$-test for $\left\{\pi_{1}, \pi_{2}\right\}$.

For bimonthly time series, i.e. in the case of $S=6$, the auxiliary regression is

$$
\phi(B) y_{5, t}=\mu_{t}+\pi_{1} y_{1, t-1}+\pi_{2} y_{2, t-1}+\pi_{3} y_{3, t-1}+\pi_{4} y_{3, t-2}+\pi_{5} y_{4, t-1}+\pi_{6} y_{4, t-2}+\varepsilon_{t}
$$




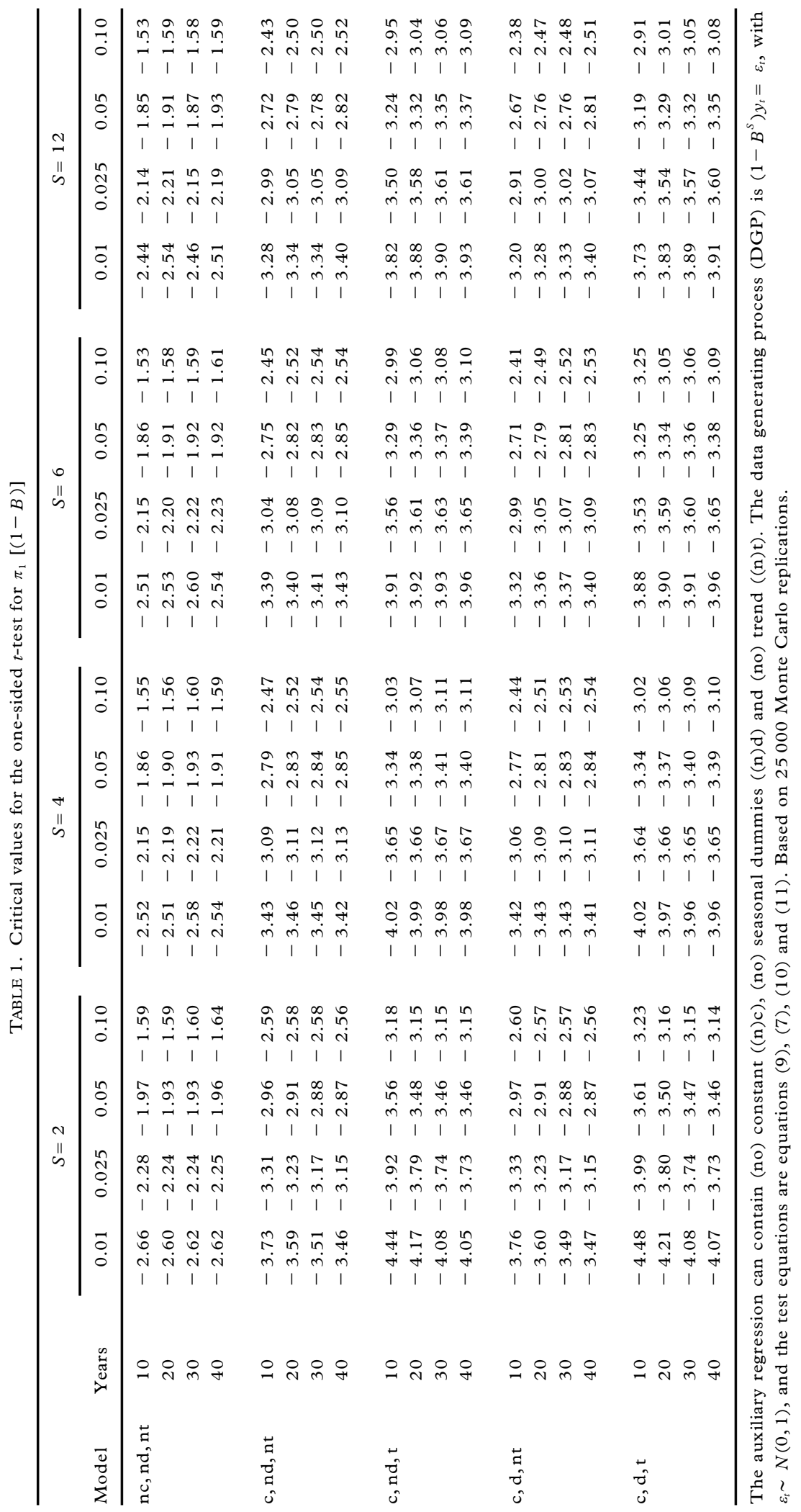




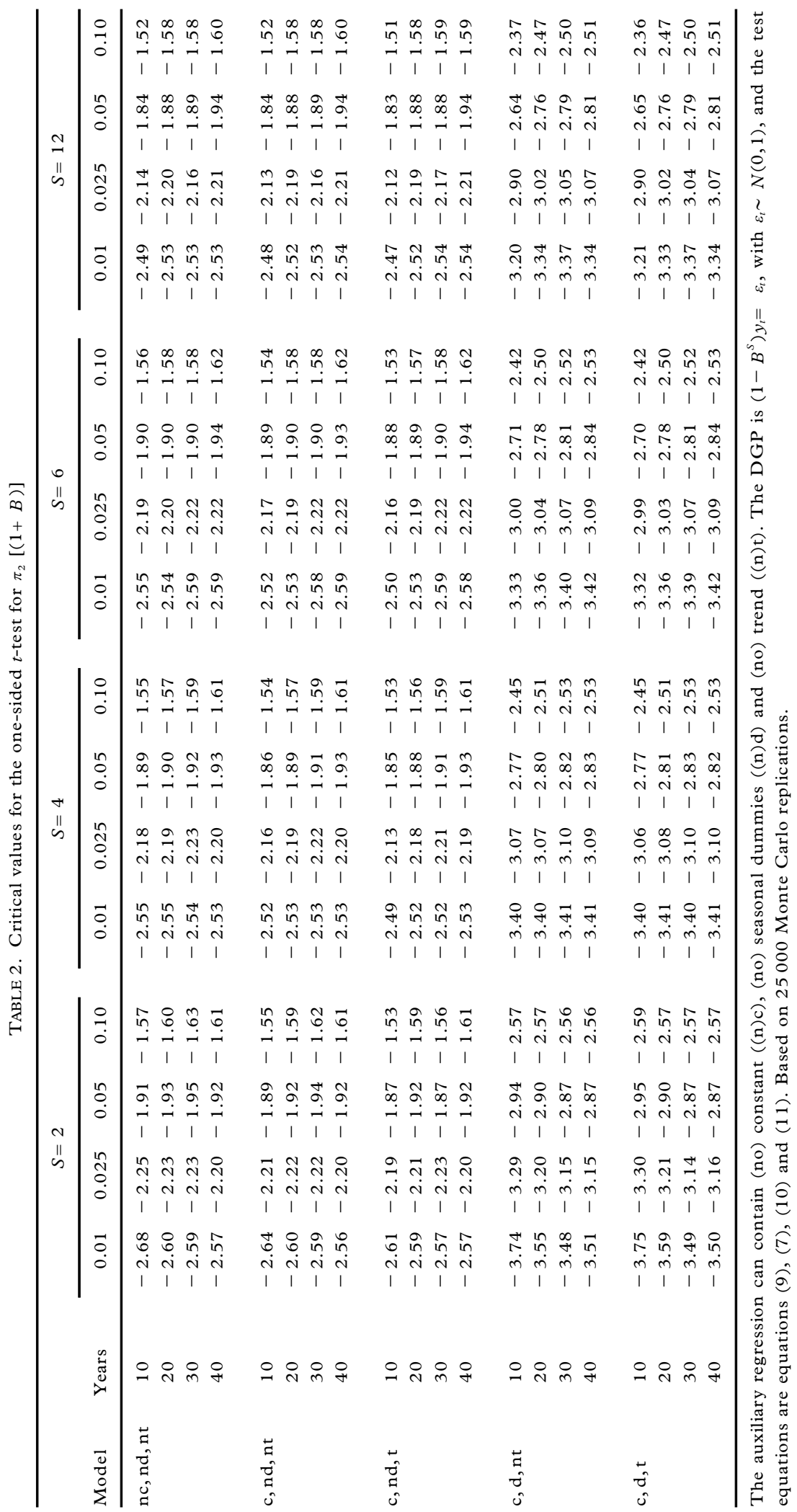


TABLE 3. Critical values for the joint $F$-test for $\pi_{3}$ and $\pi_{4}\left[\left(1+B^{2}\right)\right]$ in quarterly and monthly data

\begin{tabular}{|c|c|c|c|c|c|c|c|c|c|}
\hline \multirow[b]{2}{*}{ Model } & \multirow[b]{2}{*}{ Years } & \multicolumn{4}{|c|}{$S=4$} & \multicolumn{4}{|c|}{$S=12$} \\
\hline & & 0.10 & 0.05 & 0.025 & 0.01 & 0.10 & 0.05 & 0.025 & 0.01 \\
\hline \multirow[t]{4}{*}{$\mathrm{nc}, \mathrm{nd}, \mathrm{nt}$} & 10 & 2.44 & 3.21 & 3.99 & 5.09 & 2.33 & 3.06 & 3.76 & 4.75 \\
\hline & 20 & 2.41 & 3.15 & 3.90 & 4.91 & 2.37 & 3.05 & 3.76 & 4.64 \\
\hline & 30 & 2.38 & 3.06 & 3.75 & 4.69 & 2.38 & 3.05 & 3.74 & 4.53 \\
\hline & 40 & 2.39 & 3.11 & 3.86 & 4.85 & 2.36 & 3.07 & 3.74 & 4.74 \\
\hline \multirow[t]{4}{*}{$\mathrm{cn}, \mathrm{nd}, \mathrm{nt}$} & 10 & 2.35 & 3.06 & 3.80 & 4.95 & 2.29 & 3.01 & 3.70 & 4.66 \\
\hline & 20 & 2.37 & 3.09 & 3.81 & 4.83 & 2.36 & 3.03 & 3.72 & 4.60 \\
\hline & 30 & 2.35 & 3.01 & 3.71 & 4.61 & 2.37 & 3.05 & 3.73 & 4.51 \\
\hline & 40 & 2.37 & 3.08 & 3.82 & 4.83 & 2.36 & 3.07 & 3.73 & 4.72 \\
\hline \multirow[t]{4}{*}{$\mathrm{c}, \mathrm{nd}, \mathrm{t}$} & 10 & 2.25 & 2.94 & 3.69 & 4.70 & 2.26 & 2.97 & 3.64 & 4.55 \\
\hline & 20 & 2.32 & 3.04 & 3.73 & 4.70 & 2.34 & 3.01 & 3.69 & 4.59 \\
\hline & 30 & 2.30 & 2.98 & 3.65 & 4.57 & 2.36 & 3.04 & 3.72 & 4.45 \\
\hline & 40 & 2.35 & 3.05 & 3.79 & 4.76 & 2.35 & 3.05 & 3.72 & 4.71 \\
\hline \multirow[t]{4}{*}{$\mathrm{c}, \mathrm{d}, \mathrm{nt}$} & 10 & 5.44 & 6.63 & 7.80 & 9.32 & 4.88 & 5.82 & 6.71 & 7.91 \\
\hline & 20 & 5.47 & 6.62 & 7.65 & 8.94 & 5.28 & 6.27 & 7.12 & 8.35 \\
\hline & 30 & 5.62 & 6.70 & 7.72 & 8.97 & 5.33 & 6.35 & 7.19 & 8.40 \\
\hline & 40 & 5.52 & 6.57 & 7.57 & 8.79 & 5.45 & 6.35 & 7.36 & 8.40 \\
\hline \multirow[t]{4}{*}{$\mathrm{c}, \mathrm{d}, \mathrm{t}$} & 10 & 5.38 & 6.56 & 7.77 & 9.30 & 4.86 & 5.77 & 6.66 & 7.86 \\
\hline & 20 & 5.44 & 6.57 & 7.58 & 8.86 & 5.26 & 6.24 & 7.10 & 8.30 \\
\hline & 30 & 5.59 & 6.66 & 7.67 & 8.91 & 5.33 & 6.35 & 7.18 & 8.39 \\
\hline & 40 & 5.48 & 6.55 & 7.54 & 8.79 & 5.45 & 6.35 & 7.35 & 8.38 \\
\hline
\end{tabular}

The auxiliary regression can contain (no) constant $((\mathrm{n}) \mathrm{c})$, (no) seasonal dummies ((n)d) and (no) trend $((\mathrm{n}) \mathrm{t})$. The DGP is $\left(1-B^{S}\right) y_{t}=\varepsilon_{t}$, with $\varepsilon_{t} \sim N(0,1)$, and the test equations are equations (7) and (11). Based on 25000 Monte Carlo replications.

where $\phi(B)$ is an $\operatorname{AR}(p-6)$ polynomial, and where

$$
\begin{aligned}
& y_{5, t}=\left(1-B^{6}\right) y_{t} \\
& y_{1, t}=(1+B)\left(1+B^{2}+B^{4}\right) y_{t} \\
& y_{2, t}=-(1-B)\left(1+B^{2}+B^{4}\right) y_{t} \\
& y_{3, t}=-\left(1-B^{2}\right)\left(1+B+B^{2}\right) y_{t} \\
& y_{4, t}=-\left(1-B^{2}\right)\left(1-B+B^{2}\right) y_{t}
\end{aligned}
$$

Again, $\pi_{1}$ and $\pi_{2}$ correspond to the unit roots 1 and -1 , and we again consider (one-sided) $t$-tests for these parameters. Furthermore, we consider $F$-tests for $\left\{\pi_{3}, \pi_{4}\right\},\left\{\pi_{5}, \pi_{6}\right\},\left\{\pi_{2}, \ldots, \pi_{6}\right\}$ and $\left\{\pi_{1}, \ldots, \pi_{6}\right\}$.

Finally, for monthly time series where $S=12$, the relevant test equation is

$$
\begin{aligned}
\phi(B) y_{8, t} & =\mu_{t}+\pi_{1} y_{1, t-1}+\pi_{2} y_{2, t-1}+\pi_{2} y_{2, t-1}+\pi_{4} y_{3, t-2}+\pi_{5} y_{4, t-1} \\
& +\pi_{6} y_{4, t-2}+\pi_{7} y_{5, t-1}+\pi_{8} y_{5, t-2}+\pi_{9} y_{6, t-1}+\pi_{10} y_{6, t-2} \\
& +\pi_{11} y_{7, t-1}+\pi_{12} y_{7, t-2}+\varepsilon_{t}
\end{aligned}
$$


TABLE 4. Critical values for the joint $F$-test for $\left\{\pi_{3}, \pi_{4}\right\}$ and $\left\{\pi_{5}, \pi_{6}\right\}$ in bimonthly data

\begin{tabular}{|c|c|c|c|c|c|c|c|c|c|}
\hline \multirow[b]{2}{*}{ Model } & \multirow[b]{2}{*}{ Years } & \multicolumn{4}{|c|}{$\pi_{3}, \pi_{4}$} & \multicolumn{4}{|c|}{$\pi_{5}, \pi_{6}$} \\
\hline & & 0.10 & 0.05 & 0.025 & 0.01 & 0.10 & 0.05 & 0.025 & 0.01 \\
\hline \multirow[t]{4}{*}{$\mathrm{nc}, \mathrm{nd}, \mathrm{nt}$} & 10 & 2.39 & 3.13 & 3.86 & 4.94 & 2.35 & 3.10 & 3.89 & 4.95 \\
\hline & 20 & 2.39 & 3.14 & 3.87 & 4.84 & 2.37 & 3.11 & 3.80 & 4.84 \\
\hline & 30 & 2.40 & 3.10 & 3.85 & 4.85 & 2.41 & 3.13 & 3.80 & 4.66 \\
\hline & 40 & 2.37 & 3.07 & 3.76 & 4.76 & 2.39 & 3.14 & 3.80 & 4.72 \\
\hline \multirow[t]{4}{*}{$\mathrm{c}, \mathrm{nd}, \mathrm{nt}$} & 10 & 2.33 & 3.05 & 3.79 & 4.78 & 2.28 & 3.00 & 3.74 & 4.86 \\
\hline & 20 & 2.36 & 3.10 & 3.81 & 4.77 & 2.33 & 3.06 & 3.75 & 4.76 \\
\hline & 30 & 2.37 & 3.09 & 3.79 & 4.76 & 2.39 & 3.11 & 3.78 & 4.62 \\
\hline & 40 & 2.35 & 3.07 & 3.75 & 4.73 & 2.38 & 3.11 & 3.78 & 4.69 \\
\hline \multirow[t]{4}{*}{$\mathrm{c}, \mathrm{nd}, \mathrm{t}$} & 10 & 2.28 & 2.99 & 3.74 & 4.77 & 2.21 & 2.92 & 3.62 & 4.69 \\
\hline & 20 & 2.34 & 3.08 & 3.78 & 4.75 & 2.30 & 3.00 & 3.68 & 4.67 \\
\hline & 30 & 2.36 & 3.06 & 3.79 & 4.76 & 2.36 & 3.08 & 3.75 & 4.59 \\
\hline & 40 & 2.33 & 3.04 & 3.74 & 4.71 & 2.37 & 3.09 & 3.75 & 4.65 \\
\hline \multirow[t]{4}{*}{$\mathrm{c}, \mathrm{d}, \mathrm{nt}$} & 10 & 5.13 & 6.16 & 7.29 & 8.54 & 5.11 & 6.14 & 7.19 & 8.56 \\
\hline & 20 & 5.38 & 6.40 & 7.38 & 8.72 & 5.39 & 6.44 & 7.40 & 8.65 \\
\hline & 30 & 5.36 & 6.39 & 7.35 & 8.66 & 5.47 & 6.49 & 7.44 & 8.61 \\
\hline & 40 & 5.51 & 6.50 & 7.41 & 8.58 & 5.51 & 6.53 & 7.51 & 8.72 \\
\hline \multirow[t]{4}{*}{$\mathrm{c}, \mathrm{d}, \mathrm{t}$} & 10 & 5.09 & 6.13 & 7.17 & 8.53 & 5.05 & 6.08 & 7.13 & 8.56 \\
\hline & 20 & 5.35 & 6.36 & 7.34 & 8.68 & 5.37 & 6.41 & 7.37 & 8.61 \\
\hline & 30 & 5.33 & 6.37 & 7.36 & 8.61 & 5.46 & 6.48 & 7.41 & 8.59 \\
\hline & 40 & 5.49 & 6.47 & 7.40 & 8.59 & 5.50 & 6.52 & 7.50 & 8.68 \\
\hline
\end{tabular}

The auxiliary regression can contain (no) constant $((\mathrm{n}) \mathrm{c})$, (no) seasonal dummies $((\mathrm{n}) \mathrm{d})$ and (no) trend $((\mathrm{n}) \mathrm{t})$. The DGP is $\left(1-B^{S}\right) y_{t}=\varepsilon_{t}$, with $\varepsilon_{t} \sim N(0,1)$, and the test equation is equation (10). Based on 25000 Monte Carlo replications.

where $\phi(B)$ is an $\operatorname{AR}(p-12)$ polynomial, and where

$$
\begin{aligned}
& y_{1, t}=(1+B)\left(1+B^{2}\right)\left(1+B^{4}+B^{8}\right) y_{t} \\
& y_{2, t}=-(1-B)\left(1+B^{2}\right)\left(1+B^{4}+B^{8}\right) y_{t} \\
& y_{3, t}=-\left(1-B^{2}\right)\left(1+B^{4}+B^{8}\right) y_{t} \\
& y_{4, t}=-\left(1-B^{4}\right)\left(1-B 3^{1 / 2}+B^{2}\right)\left(1+B^{2}+B^{4}\right) y_{t} \\
& y_{5, t}=-\left(1-B^{4}\right)\left(1+B 3^{1 / 2}+B^{2}\right)\left(1+B^{2}+B^{4}\right) y_{t} \\
& y_{6, t}=-\left(1-B^{4}\right)\left(1-B^{2}+B^{4}\right)\left(1-B+B^{2}\right) y_{t} \\
& y_{7, t}=-\left(1-B^{4}\right)\left(1-B^{2}+B^{4}\right)\left(1+B+B^{2}\right) y_{t} \\
& y_{8, t}=\left(1-B^{12}\right) y_{t}
\end{aligned}
$$

Similar to the above cases, the $y_{1, t}$ and $y_{2, t}$ variables correspond to the unit roots +1 and -1 . The $y_{3, t}$ variable corresponds to the seasonal unit roots $\pm \mathrm{i}$.

For monthly time series, we generate critical values for the $t$-ratios for $\pi_{1}$ and $\pi_{2}$, for the $F$-tests for $\left\{\pi_{3}, \pi_{4}\right\},\left\{\pi_{5}, \pi_{6}\right\},\left\{\pi_{7}, \pi_{8}\right\},\left\{\pi_{9}, \pi_{10}\right\}$ and $\left\{\pi_{11}, \pi_{12}\right\}$, as well as for the $F$-tests for $\left\{\pi_{2}, \ldots, \pi_{12}\right\}$ and $\left\{\pi_{1}, \ldots, \pi_{12}\right\}$. Hence, our tables extend those of Hylleberg et al. (1990) and Ghysels et al. (1994) to other seasonal time series.

In Table 1, we present the critical values for the one-sided $t$-test for $\pi_{1}$ for 


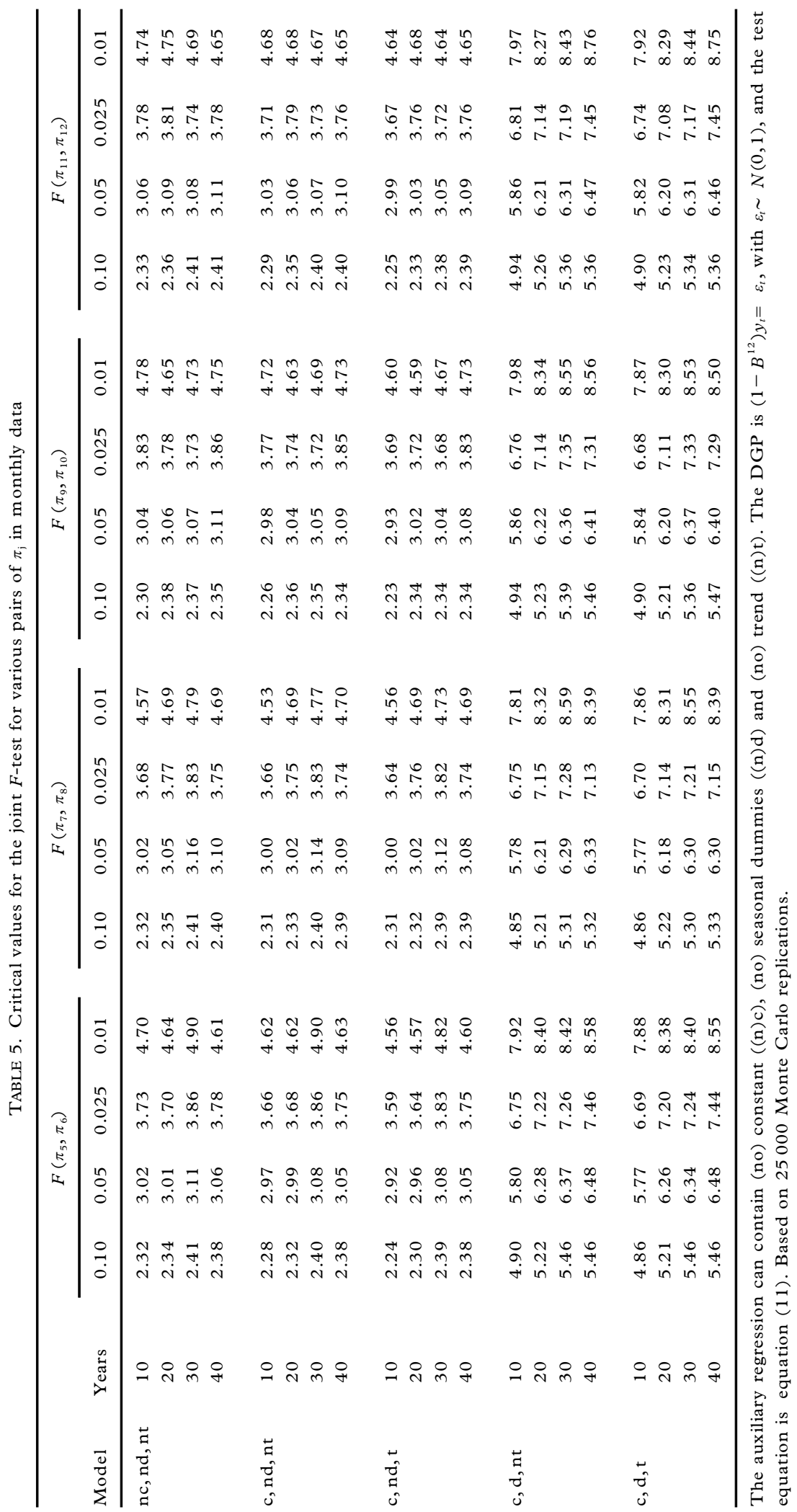




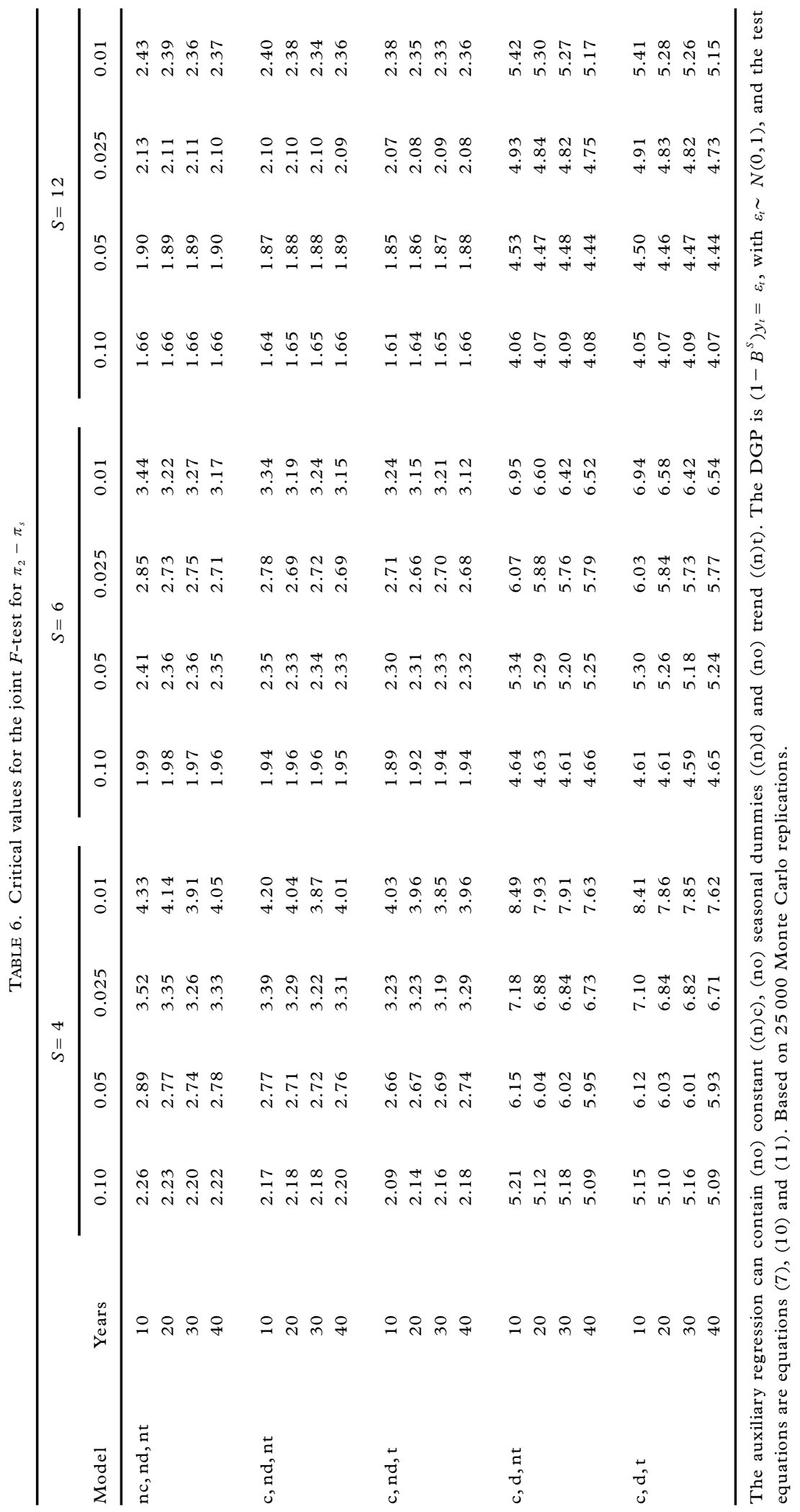




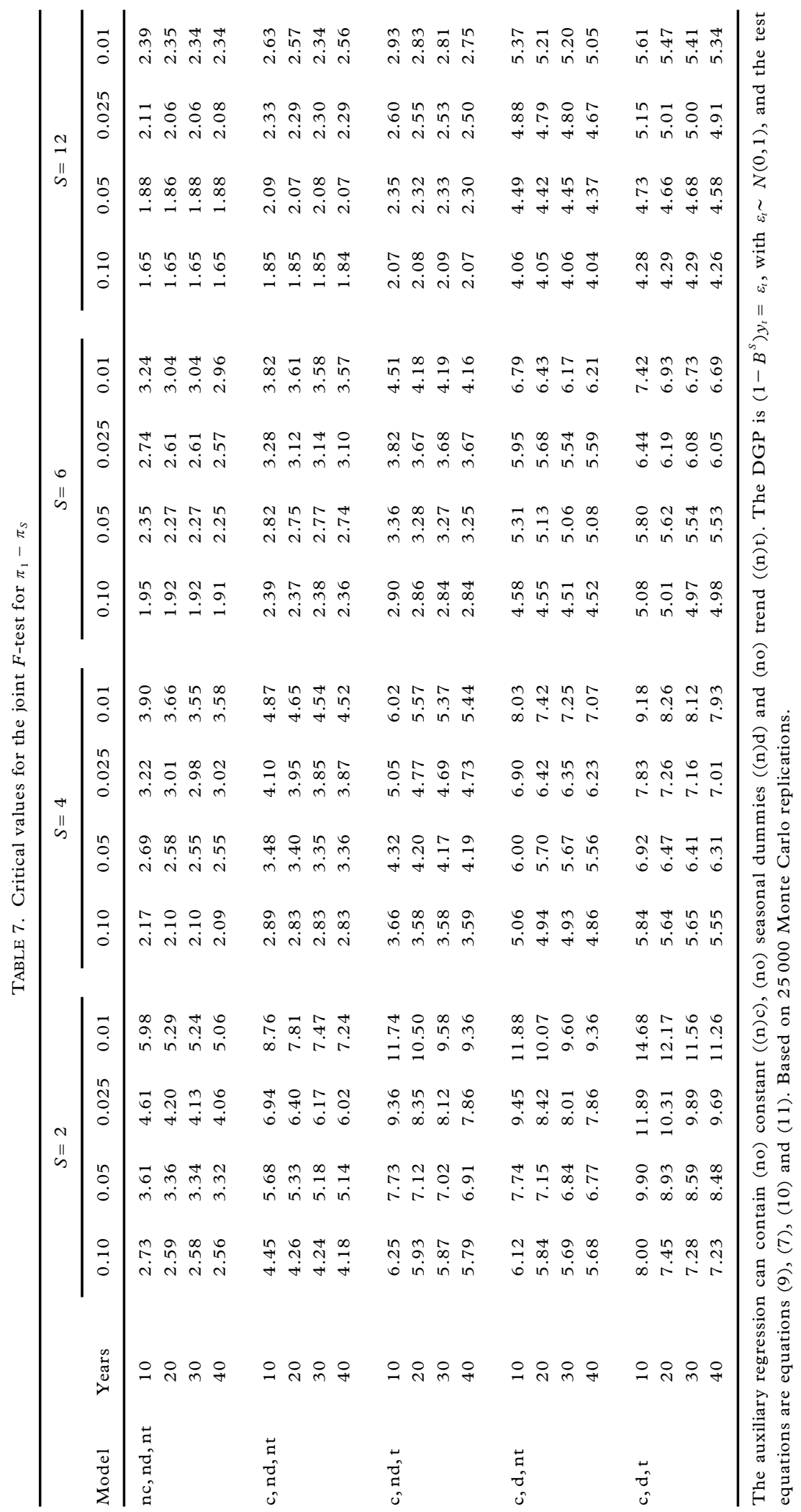


TABLE 8. An application of the test regression of Hylleberg et al. to quarterly new car sales in the Netherlands

\begin{tabular}{llccccc}
\hline Model & \multicolumn{1}{c}{ Lags $^{a}$} & $t\left(\pi_{1}\right)$ & $t\left(\pi_{2}\right)$ & $F\left(\pi_{3}, \pi_{4}\right)$ & $F\left(\pi_{2}, \pi_{3}, \pi_{4}\right)$ & $F\left(\pi_{1}, \ldots, \pi_{4}\right)$ \\
\hline nc, nd, nt & $1,2,3,4,7,8$ & 1.094 & -0.680 & 0.254 & 0.317 & 0.573 \\
c,nd, nt & $1,2,3,4,7,8$ & $-3.022^{\star \star}$ & -0.639 & 0.216 & 0.274 & 2.538 \\
c, nd, t & $1,2,3,4,7,8$ & -1.994 & -0.635 & 0.215 & 0.271 & 1.211 \\
c, d, nt & $1,3,4$ & $-3.072^{\star \star}$ & -1.442 & $7.020^{\star \star}$ & 4.913 & $6.979^{\star \star}$ \\
c, d, t & $1,3,4$ & -1.891 & -1.434 & $6.934^{\star \star}$ & 4.856 & 4.712 \\
\hline
\end{tabular}

${ }^{a}$ Lags indicates that we include $\Delta_{4} y_{t}$ at certain lags to obtain approximate white noise estimated residuals. The number of lags is selected using Lagrange multiplier tests for residual autocorrelation and the relevance of the last lag.

$\star \star \star$ Significant at the $1 \%$ level, $\star \star$ significant at the $5 \%$ level, $\star$ significant at the $10 \%$ level. The auxiliary regression is equation (7), which can include (no) constant ( $(\mathrm{c})$ ), (no) seasonal dummies $(\mathrm{n}(\mathrm{d}))$ and (no) trend $(\mathrm{n}(\mathrm{t}))$.

seasonal time series with $S=2,4,6$ and 12 . We generate critical values for the cases where

$$
\mu_{t}=\alpha_{0}+\sum_{s=1}^{s-1} \alpha_{s} D_{s t}+\beta_{0} t
$$

with various parameters set equal to zero. For example, (c, nd, t) amounts to $\alpha_{s}=0$ for $s=1, \ldots, S-1$, and (c, d, nt) corresponds to $\beta_{0}=0$. In Table 2, we report the critical values for the $t$-ratio for $\pi_{2}$ for all four seasonal time series. Table 3 concerns the $F$-test for $\left\{\pi_{3}, \pi_{4}\right\}$ in the case where $S$ is 4 or 12 . In Table 4 , we display the fractiles for the joint $F$-tests for $\left\{\pi_{3}, \pi_{4}\right\}$ and $\left\{\pi_{5}, \pi_{6}\right\}$ in the case of $S=6$, while those for all joint $F$-tests for monthly time series are given in Table 5 . In Table 6, we give the critical values for the $F$-tests for $\left\{\pi_{2}, \ldots, \pi_{S}\right)$ for $S=4,6$ and 12, while Table 7 shows those for the $F$-tests for $\left\{\pi_{1}, \ldots, \pi_{S}\right\}$ for $S=2,4,6$ and 12. Critical values are generated for $10,20,30$ and 40 years of observations.

An application of the procedure of Hylleberg et al. (1990) to the quarterly data on new car sales in the Netherlands yields the results reported in Table 8.

It appears that only when we exclude a deterministic trend do we reject the presence of a non-seasonal unit root at the $5 \%$ level. The finding of a unit root at the biannual frequency, which is checked using the $t\left(\pi_{2}\right)$-test, appears robust to model specification. When we include seasonal dummies, the evidence for the roots $\mathrm{i}$ and $-\mathrm{i}$ disappears based on the $F\left(\pi_{3}, \pi_{4}\right)$-test statistics. The joint tests for the various $\pi_{\mathrm{i}}$ terms generally suggest that all unit roots are present. In sum, new car sales may be transformed to stationarity by the $\left(1-B^{4}\right)$ or by the $\left(1-B^{2}\right)$ differencing filter.

\section{Non-seasonal and all seasonal unit roots}

In the previous section, we considered quarterly and monthly time series, for which seasonal unit roots can be meaningfully interpreted. Indeed, it may sometimes be required to filter monthly time series using the $\left(1-B 3^{1 / 2}+B^{2}\right.$ ) filter (see, for example, Abraham \& Box, 1978). However, for time series with an uneven seasonal frequency, such as 5 for daily observations or 13 for four-weekly observations, such useful filters cannot be found. In fact, for such time series, one may only be interested in selecting between $\left(1-B^{S}\right),(1-B),\left(1+B+\ldots+B^{S-1}\right)$ and no 
TABLE 9. Critical values for the one-sided $t$-test for $\pi_{1}$ and $\pi_{2}$

\begin{tabular}{|c|c|c|c|c|c|c|c|c|c|}
\hline \multirow[b]{2}{*}{ Model } & \multirow[b]{2}{*}{ Years } & \multicolumn{4}{|c|}{$t\left(\pi_{1}\right)$} & \multicolumn{4}{|c|}{$t\left(\pi_{2}\right)$} \\
\hline & & 0.01 & 0.025 & 0.05 & 0.10 & 0.01 & 0.025 & 0.05 & 0.10 \\
\hline \multicolumn{10}{|l|}{$S=4$} \\
\hline \multirow[t]{2}{*}{$\mathrm{nc}, \mathrm{nd}, \mathrm{nt}$} & 10 & -2.55 & -2.15 & -1.82 & -1.44 & -2.64 & -2.26 & -1.94 & -1.59 \\
\hline & 20 & -2.51 & -2.13 & -1.83 & -1.47 & -2.57 & -2.22 & -1.93 & -1.60 \\
\hline \multirow[t]{2}{*}{$\mathrm{c}, \mathrm{nd}, \mathrm{nt}$} & 10 & -2.49 & -2.10 & -1.79 & -1.42 & -3.56 & -3.18 & -2.87 & -2.56 \\
\hline & 20 & -2.49 & -2.13 & -1.83 & -1.47 & -3.47 & -3.12 & -2.85 & -2.54 \\
\hline \multirow[t]{2}{*}{$\mathrm{c}, \mathrm{nd}, \mathrm{t}$} & 10 & -2.45 & -2.06 & -1.76 & -1.39 & -4.09 & -3.74 & -3.44 & -3.11 \\
\hline & 20 & -2.48 & -2.11 & -1.82 & -1.45 & -4.02 & -3.68 & -3.42 & -3.11 \\
\hline \multirow[t]{2}{*}{$\mathrm{c}, \mathrm{d}, \mathrm{nt}$} & 10 & -4.14 & -3.72 & -3.40 & -3.05 & -3.49 & -3.10 & -2.81 & -2.49 \\
\hline & 20 & -4.10 & -3.76 & -3.45 & -3.09 & -3.42 & -3.08 & -2.82 & -2.51 \\
\hline \multirow[t]{2}{*}{$c, d, t$} & 10 & -4.09 & -3.71 & -3.39 & -3.04 & -4.01 & -3.63 & -3.34 & -3.02 \\
\hline & 20 & -4.08 & -3.73 & -3.44 & -3.08 & -3.95 & -3.63 & -3.37 & -3.07 \\
\hline \multicolumn{10}{|l|}{$S=13$} \\
\hline \multirow[t]{2}{*}{$\mathrm{nc}, \mathrm{nd}, \mathrm{nt}$} & 10 & -2.41 & -2.06 & -1.74 & -1.37 & -2.60 & -2.24 & -1.94 & -1.61 \\
\hline & 20 & -2.43 & -2.06 & -1.74 & -1.38 & -2.56 & -2.22 & -1.94 & -1.61 \\
\hline \multirow[t]{2}{*}{$\mathrm{c}, \mathrm{nd}, \mathrm{nt}$} & 10 & -2.40 & -2.04 & -1.73 & -1.36 & -3.51 & -3.16 & -2.88 & -2.56 \\
\hline & 20 & -2.41 & -2.05 & -1.73 & -1.37 & -3.45 & -3.12 & -2.86 & -2.57 \\
\hline \multirow[t]{2}{*}{$\mathrm{c}, \mathrm{nd}, \mathrm{t}$} & 10 & -2.38 & -2.03 & -1.71 & -1.35 & -4.03 & -3.70 & -3.43 & -3.12 \\
\hline & 20 & -2.40 & -2.04 & -1.72 & -1.37 & -3.97 & -3.68 & -3.43 & -3.14 \\
\hline \multirow[t]{2}{*}{$\mathrm{c}, \mathrm{d}, \mathrm{nt}$} & 10 & -5.39 & -5.01 & -4.68 & -4.31 & -3.42 & -3.08 & -2.78 & -2.48 \\
\hline & 20 & -5.40 & -5.05 & -4.74 & -4.38 & -3.40 & -3.07 & -2.81 & -2.52 \\
\hline \multirow[t]{2}{*}{$\mathrm{c}, \mathrm{d}, \mathrm{t}$} & 10 & -5.41 & -5.02 & -4.69 & -4.32 & -3.90 & -3.59 & -3.31 & -3.00 \\
\hline & 20 & -5.40 & -5.05 & -4.75 & -4.39 & -3.91 & -3.60 & -3.36 & -3.07 \\
\hline \multicolumn{10}{|l|}{$S=5$} \\
\hline \multirow[t]{2}{*}{$\mathrm{nc}, \mathrm{nd}, \mathrm{nt}$} & 2 & -2.52 & -2.14 & -1.84 & -1.48 & -2.54 & -2.23 & -1.93 & -1.61 \\
\hline & 5 & -2.51 & -2.13 & -1.82 & -1.47 & -2.57 & -2.23 & -1.96 & -1.64 \\
\hline \multirow[t]{2}{*}{$\mathrm{c}, \mathrm{nd}, \mathrm{nt}$} & 2 & -2.51 & -2.13 & -1.84 & -1.48 & -3.44 & -3.12 & -2.87 & -2.56 \\
\hline & 5 & -2.51 & -2.13 & -1.82 & -1.47 & -3.43 & -3.11 & -2.86 & -2.57 \\
\hline \multirow[t]{2}{*}{$\mathrm{c}, \mathrm{nd}, \mathrm{t}$} & 2 & -2.50 & -2.13 & -1.84 & -1.47 & -3.97 & -3.68 & -3.41 & -3.11 \\
\hline & 5 & -2.51 & -2.13 & -1.82 & -1.47 & -3.94 & -3.64 & -3.40 & -3.12 \\
\hline \multirow[t]{2}{*}{$\mathrm{c}, \mathrm{d}, \mathrm{nt}$} & 2 & -4.32 & -3.97 & -3.65 & -3.31 & -3.40 & -3.11 & -2.84 & -2.54 \\
\hline & 5 & -4.35 & -3.98 & -3.67 & -3.33 & -3.42 & -3.10 & -2.86 & -2.57 \\
\hline \multirow[t]{2}{*}{$c, d, t$} & 2 & -4.32 & -3.98 & -3.64 & -3.31 & -3.94 & -3.64 & -3.39 & -3.09 \\
\hline & 5 & -4.35 & -3.98 & -3.67 & -3.33 & -3.93 & -3.64 & -3.40 & -3.11 \\
\hline
\end{tabular}

The auxiliary regression can contain (no) constant $((n) c)$, (no) seasonal dummies $((n) d)$ and (no) trend $((\mathrm{n}) \mathrm{t})$. The DGP is $\left(1-B^{S}\right) y_{t}=\varepsilon_{t}$, with $\varepsilon_{t} \sim N(0,1)$, and the test equation is equation (12). Based on 25000 Monte Carlo replications.

filter, i.e. a selection that involves the non-seasonal unit root while all seasonal unit roots are considered jointly. The auxiliary regression that can be useful for this purpose is an extension of the method of Osborn et al. (1988), i.e.

$$
\phi(B) \Delta_{S} y_{t}=\mu_{t}+\pi_{1}(-1+B) y_{t-(S-1)}+\pi_{2}\left(1+B+\ldots+B^{S-1}\right) y_{t-1}+\varepsilon_{t}
$$

where $\phi(B)$ is an $\operatorname{AR}(p-S)$ polynomial, and where $\mu_{t}$ is given similarly to equation 
TABLE 10. Critical values for the $F$-test for $\pi_{1}$ and $\pi_{2}$

\begin{tabular}{|c|c|c|c|c|c|}
\hline Model & Years & 0.10 & 0.05 & 0.025 & 0.01 \\
\hline \multicolumn{6}{|l|}{$S=4$} \\
\hline \multirow[t]{2}{*}{$\mathrm{nc}, \mathrm{nd}, \mathrm{nt}$} & 10 & 2.55 & 3.37 & 4.21 & 5.44 \\
\hline & 20 & 2.54 & 3.28 & 4.01 & 4.98 \\
\hline \multirow[t]{2}{*}{$\mathrm{c}, \mathrm{nd}, \mathrm{nt}$} & 10 & 4.19 & 5.24 & 6.23 & 7.55 \\
\hline & 20 & 4.08 & 5.05 & 6.02 & 7.29 \\
\hline \multirow[t]{2}{*}{$\mathrm{c}, \mathrm{nd}, \mathrm{t}$} & 10 & 5.79 & 7.01 & 8.12 & 9.85 \\
\hline & 20 & 5.69 & 6.81 & 7.86 & 9.20 \\
\hline \multirow[t]{2}{*}{$\mathrm{c}, \mathrm{d}, \mathrm{nt}$} & 10 & 6.95 & 8.42 & 9.92 & 12.11 \\
\hline & 20 & 6.90 & 8.30 & 9.52 & 11.29 \\
\hline \multirow[t]{2}{*}{$c, d, t$} & 10 & 8.53 & 10.25 & 12.04 & 14.12 \\
\hline & 20 & 8.34 & 9.86 & 11.34 & 13.24 \\
\hline \multicolumn{6}{|l|}{$S=13$} \\
\hline \multirow[t]{2}{*}{$\mathrm{nc}, \mathrm{nd}, \mathrm{nt}$} & 10 & 2.48 & 3.22 & 4.00 & 4.91 \\
\hline & 20 & 2.45 & 3.17 & 3.91 & 4.84 \\
\hline \multirow[t]{2}{*}{$\mathrm{c}, \mathrm{nd}, \mathrm{nt}$} & 10 & 4.09 & 5.04 & 5.98 & 7.02 \\
\hline & 20 & 4.09 & 4.94 & 5.81 & 6.94 \\
\hline \multirow[t]{2}{*}{$\mathrm{c}, \mathrm{nd}, \mathrm{t}$} & 10 & 5.65 & 6.68 & 7.72 & 9.06 \\
\hline & 20 & 5.63 & 6.69 & 7.64 & 8.85 \\
\hline \multirow[t]{2}{*}{$\mathrm{c}, \mathrm{d}, \mathrm{nt}$} & 10 & 11.21 & 13.11 & 14.87 & 17.16 \\
\hline & 20 & 11.51 & 13.26 & 14.87 & 16.91 \\
\hline \multirow[t]{2}{*}{$\mathrm{c}, \mathrm{d}, \mathrm{t}$} & 10 & 12.59 & 14.61 & 16.49 & 18.83 \\
\hline & 20 & 12.83 & 14.71 & 16.34 & 18.66 \\
\hline \multicolumn{6}{|l|}{$S=5$} \\
\hline \multirow[t]{2}{*}{$\mathrm{nc}, \mathrm{nd}, \mathrm{nt}$} & 2 & 2.48 & 3.21 & 3.88 & 4.80 \\
\hline & 5 & 2.45 & 3.15 & 3.88 & 4.83 \\
\hline \multirow[t]{2}{*}{$\mathrm{c}, \mathrm{nd}, \mathrm{nt}$} & 2 & 4.08 & 4.97 & 5.87 & 7.07 \\
\hline & 5 & 4.09 & 4.93 & 5.78 & 6.86 \\
\hline \multirow[t]{2}{*}{$\mathrm{c}, \mathrm{nd}, \mathrm{t}$} & 2 & 5.62 & 6.64 & 7.70 & 8.95 \\
\hline & 5 & 5.59 & 6.56 & 7.56 & 8.66 \\
\hline \multirow[t]{2}{*}{$\mathrm{c}, \mathrm{d}, \mathrm{nt}$} & 2 & 7.53 & 8.93 & 10.12 & 11.75 \\
\hline & 5 & 7.58 & 8.88 & 10.10 & 11.64 \\
\hline \multirow[t]{2}{*}{$c, d, t$} & 2 & 8.91 & 10.32 & 11.71 & 13.42 \\
\hline & 5 & 8.95 & 10.32 & 11.62 & 13.26 \\
\hline
\end{tabular}

The auxiliary regression can contain (no) constant $((\mathrm{n}) \mathrm{c})$, (no) seasonal dummies $((\mathrm{n}) \mathrm{d})$ and (no) trend $((\mathrm{n}) \mathrm{t})$. The DGP is $\left(1-B^{S}\right) y_{t}=\varepsilon_{t}$, with $\varepsilon_{t} \sim N(0,1)$, and the test equation is equation (12). Based on 25000 Monte Carlo replications.

(8). The test boils down to checking if either $\pi_{1}$ or $\pi_{2}$ is equal to zero (or if they both are). There are four possible outcomes. The first possibility is that $\pi_{1}=\pi_{2}=0$, which implies that $\left(1-B^{S}\right)$ is useful. The second possibility is that $\pi_{1}=0$ and $\pi_{2} \neq 0$, implying that $\left(1+B+\ldots+B^{S-1}\right)$ is an adequate filter and, hence, that there are $S-1$ seasonal unit roots. The third possibility is that $\pi_{1} \neq 0$ and $\pi_{2}=0$, implying that $(1-B)$ is the appropriate differencing filter. Finally, when both $\pi_{1}$ and $\pi_{2}$ are not equal to zero, no filter is needed. 
TABLE 11. Testing for non-seasonal and all seasonal unit roots in quarterly new car sales in the Netherlands

\begin{tabular}{llccc}
\hline Model & \multicolumn{1}{c}{ Lags $^{a}$} & $t\left(\pi_{1}\right)$ & $t\left(\pi_{2}\right)$ & $F\left(\pi_{1}, \pi_{2}\right)$ \\
\hline nc, nd, nt & $1,2,3,4,7,8$ & -0.415 & 1.153 & 0.764 \\
cc, nd, nt & $1,2,3,4,7,8$ & -0.418 & $-3.075^{\star \star}$ & $4.819^{\star}$ \\
c, nd, t & $1,2,3,4,7,8$ & -0.415 & -2.018 & 2.131 \\
c, d, nt & $1,2,4$ & $3.379^{\star}$ & $-3.268^{\star \star}$ & $11.878^{\star \star \star}$ \\
c, d, t & $1,2,4$ & $-3.324^{\star}$ & -1.926 & 7.423 \\
\hline
\end{tabular}

${ }^{a}$ Lags indicates that we include $\Delta_{4} y_{t}$ at certain lags to obtain approximate white noise estimated residuals. The number of lags is selected using Lagrange multiplier tests for residual autocorrelation and the relevance of the last lag.

${ }^{\star \star \star}$ Significant at the $1 \%$ level, ${ }^{\star \star}$ significant at the $5 \%$ level, ${ }^{\star}$ significant at the $10 \%$ level. The auxiliary regression is equation (12), which can include (no) constant (n(c)), (no) seasonal dummies (n(d)) and (no) trend $(\mathrm{n}(\mathrm{t}))$.

There are three test statistics for the relevant hypotheses, i.e. one-sided $t$-tests for $\pi_{1}$ and $\pi_{2}$, and an $F$-test statistic for $\left\{\pi_{1}, \pi_{2}\right\}$. In Tables 9 and 10, we report some critical values for these test statistics for 10 and 20 years of observations when $S$ is equal to 4 and 13, and for 2 and 5 years of data in the case of $S=5$.

We consider $S=4$ for comparison purposes because the $t$-test for $\pi_{2}$ can be expected to follow the same distribution as that for the $t$-test for $\pi_{1}$ in the auxiliary regression of equation (7). Furthermore, it may be expected that (as also given in the results in Table 1 ) the $t\left(\pi_{2}\right)$ distribution is similar across seasonal frequencies $S$. Differences across $S$ may appear in the distribution of the $t$-test for $\pi_{1}$, as can be observed from Table 9.

In Table 11, we report the various results of the application of this method to the quarterly new car sales data. It appears that $t\left(\pi_{1}\right)$ in equation (12) is only significant at the $10 \%$ level when the regression includes seasonal dummy variables. Furhermore, $t\left(\pi_{2}\right)$ is significant at the $5 \%$ level when the model does not include a trend. Notice that this compares with the $t\left(\pi_{1}\right)$ results in Table 8 . Overall, the results in Table 11 suggest that the $\left(1+B+B^{2}+B^{3}\right)$ filter may be useful and that, for some models, the $(1-B)$ filter is useful. The results are rather mixed, however, as could be expected from the results in Table 8 .

\section{Two non-seasonal unit roots}

In this section, we give critical values for the test of Osborn et al. (1988) in its original version, i.e. the test regression is

$$
\phi(B) \Delta_{1} \Delta_{S} y_{t}=\mu_{t}+\pi_{1}\left(1-B^{S}\right) y_{t-1}+\pi_{2}(1-B) y_{t-s}+\varepsilon_{t}
$$

where $\mu_{t}$ can be

$$
\mu_{t}=\alpha_{0}+\sum_{s=1}^{s-1} \alpha_{s} D_{s t}+\beta_{0} t+\sum_{s=1}^{s-1} \beta_{s} D_{s s} t
$$

In the method of Osborn et al., the case where all the $\beta_{0}, \ldots, \beta_{S-1}$ terms are equal to zero is considered. However, Franses and Koehler (1996) propose using equation (13) with the $\beta$ parameters not equal to zero in order to be able to select between models for time series with increasing seasonal variation.

Similar to the method described in the previous section, the appropriate selection 
TABLE 12. Critical values for tests for differencing filter

\begin{tabular}{|c|c|c|c|c|c|c|c|c|c|}
\hline \multirow[b]{2}{*}{ Model } & \multirow[b]{2}{*}{ years } & \multicolumn{4}{|c|}{$S=4$} & \multicolumn{4}{|c|}{$S=12$} \\
\hline & & 0.01 & 0.025 & 0.05 & 0.10 & 0.01 & 0.025 & 0.05 & 0.10 \\
\hline \multicolumn{10}{|l|}{$t=\left(\pi_{1}\right)$} \\
\hline \multirow{4}{*}{$\mathrm{nt}, \mathrm{ndt}$} & 10 & -2.81 & -2.42 & -2.08 & -1.69 & -2.72 & -2.42 & -2.10 & -1.74 \\
\hline & 20 & -2.82 & -2.45 & -2.11 & -1.72 & -2.84 & -2.49 & -2.17 & -1.80 \\
\hline & 30 & -2.85 & -2.44 & -2.08 & -1.71 & -2.87 & -2.50 & -2.18 & -1.82 \\
\hline & 40 & -2.81 & -2.43 & -2.11 & -1.72 & -2.87 & -2.49 & -2.18 & -1.81 \\
\hline \multirow[t]{4}{*}{$t, n d t$} & 10 & -3.53 & -3.16 & -2.83 & -2.45 & -3.47 & -3.14 & -2.82 & -2.49 \\
\hline & 20 & -3.49 & -3.15 & -2.83 & -2.47 & -3.49 & -3.16 & -2.89 & -2.53 \\
\hline & 30 & -3.45 & -3.13 & -2.82 & -2.48 & -3.53 & -3.17 & -2.89 & -2.56 \\
\hline & 40 & -3.51 & -3.14 & -2.83 & -2.48 & -3.55 & -3.18 & -2.88 & -2.56 \\
\hline \multirow[t]{4}{*}{$\mathrm{t}, \mathrm{dt}$} & 10 & -2.96 & -2.52 & -2.11 & -1.70 & -2.85 & -2.44 & -2.11 & -1.71 \\
\hline & 20 & -2.91 & -2.48 & -2.11 & -1.71 & -2.88 & -2.50 & -2.15 & -1.77 \\
\hline & 30 & -2.84 & -2.48 & -2.13 & -1.73 & -2.94 & -2.53 & -2.18 & -1.79 \\
\hline & 40 & -2.87 & -2.48 & -2.15 & -1.74 & -2.94 & -2.53 & -2.17 & -1.79 \\
\hline \multicolumn{10}{|l|}{$t\left(\pi_{2}\right)$} \\
\hline \multirow[t]{4}{*}{$\mathrm{nt}, \mathrm{ndt}$} & 10 & -4.57 & -4.15 & -3.83 & -3.46 & -6.38 & -5.99 & -5.67 & -5.30 \\
\hline & 20 & -4.39 & -4.05 & -3.75 & -3.44 & -6.27 & -5.95 & -5.63 & -5.30 \\
\hline & 30 & -4.36 & -4.04 & -3.75 & -3.43 & -6.25 & -5.91 & -5.63 & -5.30 \\
\hline & 40 & -4.34 & -4.03 & -3.76 & -3.44 & -6.26 & -5.91 & -5.64 & -5.32 \\
\hline \multirow[t]{4}{*}{$\mathrm{t}, \mathrm{ndt}$} & 10 & -4.58 & -4.17 & -3.83 & -3.47 & -6.37 & -5.98 & -5.67 & -5.30 \\
\hline & 20 & -4.39 & -4.05 & -3.75 & -3.44 & -6.28 & -5.95 & -5.64 & -5.30 \\
\hline & 30 & -4.37 & -4.03 & -3.75 & -3.43 & -6.26 & -5.91 & -5.63 & -5.30 \\
\hline & 40 & -4.34 & -4.04 & -3.77 & -3.44 & -6.26 & -5.91 & -5.64 & -5.32 \\
\hline \multirow[t]{4}{*}{$\mathrm{t}, \mathrm{dt}$} & 10 & -5.81 & -5.39 & -5.04 & -4.65 & -8.74 & -8.35 & -8.04 & -7.67 \\
\hline & 20 & -5.54 & -5.20 & -4.90 & -4.56 & -8.50 & -8.18 & -7.90 & -7.58 \\
\hline & 30 & -5.45 & -5.14 & -4.86 & -4.54 & -8.43 & -8.11 & -7.85 & -7.53 \\
\hline & 40 & -5.45 & -5.12 & -4.85 & -4.53 & -8.43 & -8.11 & -7.84 & -7.53 \\
\hline \multicolumn{10}{|c|}{$F\left(\pi_{1}, \pi_{2}\right)$} \\
\hline \multirow[t]{4}{*}{$\mathrm{nt}, \mathrm{ndt}$} & 10 & 14.02 & 11.70 & 10.02 & 8.37 & 22.82 & 20.11 & 18.16 & 16.01 \\
\hline & 20 & 12.53 & 10.82 & 9.46 & 8.03 & 21.72 & 19.70 & 17.91 & 15.95 \\
\hline & 30 & 12.16 & 10.60 & 9.36 & 8.01 & 21.82 & 19.69 & 17.87 & 15.91 \\
\hline & 40 & 12.19 & 10.54 & 9.34 & 8.05 & 21.61 & 19.48 & 17.77 & 15.94 \\
\hline \multirow[t]{4}{*}{$t, \mathrm{ndt}$} & 10 & 16.03 & 13.64 & 11.76 & 9.89 & 24.04 & 21.66 & 19.57 & 17.31 \\
\hline & 20 & 14.55 & 12.65 & 11.13 & 9.57 & 23.25 & 20.97 & 19.28 & 17.23 \\
\hline & 30 & 13.90 & 12.23 & 10.92 & 9.41 & 23.42 & 21.10 & 19.18 & 17.25 \\
\hline & 40 & 14.00 & 12.17 & 10.86 & 9.46 & 23.19 & 20.96 & 19.23 & 17.27 \\
\hline \multirow[t]{4}{*}{$\mathrm{t}, \mathrm{dt}$} & 10 & 22.43 & 19.41 & 17.03 & 14.76 & 42.24 & 38.96 & 35.93 & 32.73 \\
\hline & 20 & 19.89 & 17.72 & 15.92 & 14.06 & 39.91 & 36.87 & 34.45 & 31.97 \\
\hline & 30 & 19.11 & 17.08 & 15.49 & 13.77 & 39.16 & 36.28 & 34.02 & 31.47 \\
\hline & 40 & 18.77 & 16.97 & 15.41 & 13.72 & 39.16 & 36.18 & 33.89 & 31.46 \\
\hline
\end{tabular}

The auxiliary regression contains (no) trend $((n) t)$ and (no) seasonal trends ((n)dt). The DGP is $(1-B)\left(1-B^{S}\right) y_{t}=\varepsilon_{t}$, with $\varepsilon_{t} \sim N(0,1)$, and the test equation is equation (13). Based on 25000 Monte Carlo replications. 
TABLE 13. Testing for two non-seasonal unit roots and seasonal unit roots using the method of Osborn et al. in quarterly new car sales in the Netherlands

\begin{tabular}{llccc}
\hline Model & \multicolumn{1}{c}{$\operatorname{Lags}^{a}$} & $t\left(\pi_{1}\right)$ & $t\left(\pi_{2}\right)$ & $F\left(\pi_{1}, \pi_{2}\right)$ \\
\hline $\mathrm{nc}, \mathrm{ndt}$ & $1,3,5$ & $-3.782^{\star \star \star}$ & -3.176 & $18.339^{\star \star \star}$ \\
$\mathrm{t}, \mathrm{ndt}$ & $1,3,5$ & $-4.307^{\star \star \star}$ & -3.132 & $20.950^{\star \star \star}$ \\
$\mathrm{t}, \mathrm{dt}$ & $1,3,4,5,6$ & $-3.271^{\star \star \star}$ & $-5.338^{\star}$ & $27.252^{\star \star \star}$ \\
\hline
\end{tabular}

${ }^{a}$ Lags indicate that we include $\Delta_{1} \Delta_{4} y_{t}$ at certain lags to obtain approximate white noise estimated residuals. The number of lags is selected using Lagrange multiplier tests for residual autocorrelation and the relevance of the last lag.

$\star \star \star$ Significant at the $1 \%$ level, ${ }^{\star \star}$ significant at the $5 \%$ level, ${ }^{\star}$ significant at the $10 \%$ level. The auxiliary regression is equation (13), which can include (no) trends (nt, ndt), a trend but no seasonal trend $(t, n d t)$, or a trend and seasonal trends $(t, d t)$.

TABLE 14. Critical values for a test for a non-seasonal unit root in quarterly data with possible structural breaks at a fraction $\lambda$ of the data

\begin{tabular}{|c|c|c|c|c|c|c|c|c|c|}
\hline \multirow[b]{2}{*}{ Model } & \multirow[b]{2}{*}{$\lambda$} & \multicolumn{4}{|c|}{ Constant seasonal variation } & \multicolumn{4}{|c|}{ Varying seasonal variation } \\
\hline & & 0.01 & 0.025 & 0.05 & 0.10 & 0.01 & 0.025 & 0.05 & 0.10 \\
\hline \multirow[t]{5}{*}{$\mathrm{nc}, \mathrm{nd}, \mathrm{nt}$} & 0.25 & -2.53 & -2.17 & -1.88 & -1.55 & -3.17 & -2.82 & -2.53 & -2.20 \\
\hline & 0.40 & -2.44 & -2.12 & -1.84 & -1.53 & -3.12 & -2.77 & -2.44 & -2.09 \\
\hline & 0.50 & -2.48 & -2.16 & -1.88 & -1.56 & -3.04 & -2.67 & -2.36 & -2.02 \\
\hline & 0.60 & -2.49 & -2.16 & -1.87 & -1.54 & -3.04 & -2.63 & -2.32 & -1.95 \\
\hline & 0.75 & -2.46 & -2.14 & -1.85 & -1.53 & -2.82 & -2.46 & -2.15 & -1.80 \\
\hline \multirow[t]{5}{*}{$\mathrm{c}, \mathrm{nd}, \mathrm{nt}$} & 0.25 & -3.40 & -3.03 & -2.76 & -2.45 & -3.80 & -3.44 & -3.15 & -2.82 \\
\hline & 0.40 & -3.35 & -3.03 & -2.76 & -2.46 & -3.85 & -3.52 & -3.24 & -2.93 \\
\hline & 0.50 & -3.36 & -3.03 & -2.76 & -2.45 & -3.89 & -3.53 & -3.24 & -2.94 \\
\hline & 0.60 & -3.35 & -3.03 & -2.75 & -2.46 & -3.81 & -3.49 & -3.22 & -2.91 \\
\hline & 0.75 & -3.40 & -3.03 & -2.76 & -2.46 & -3.77 & -3.43 & -3.14 & -2.82 \\
\hline \multirow[t]{5}{*}{$\mathrm{c}, \mathrm{nd}, \mathrm{t}$} & 0.25 & -3.90 & -3.57 & -3.30 & -3.00 & -4.29 & -3.92 & -3.64 & -3.34 \\
\hline & 0.40 & -3.88 & -3.55 & -3.30 & -2.99 & -4.23 & -3.88 & -3.62 & -3.31 \\
\hline & 0.50 & -3.87 & -3.56 & -3.29 & -3.01 & -4.21 & -3.89 & -3.60 & -3.29 \\
\hline & 0.60 & -3.91 & -3.55 & -3.28 & -3.01 & -4.22 & -3.90 & -3.61 & -3.30 \\
\hline & 0.75 & -3.87 & -3.56 & -3.30 & -3.01 & -4.20 & -3.90 & -3.64 & -3.33 \\
\hline \multirow[t]{5}{*}{$\mathrm{c}, \mathrm{d}, \mathrm{nt}$} & 0.25 & -3.36 & -3.03 & -2.76 & -2.45 & -3.78 & -3.44 & -3.14 & -2.82 \\
\hline & 0.40 & -3.35 & -3.03 & -2.76 & -2.47 & -3.88 & -3.52 & -3.25 & -2.93 \\
\hline & 0.50 & -3.34 & -3.05 & -2.77 & -2.46 & -3.90 & -3.54 & -3.26 & -2.96 \\
\hline & 0.60 & -3.38 & -3.04 & -2.76 & -2.47 & -3.84 & -3.51 & -3.24 & -2.93 \\
\hline & 0.75 & -3.40 & -3.04 & -2.78 & -2.47 & -3.79 & -3.44 & -3.15 & -2.83 \\
\hline \multirow[t]{5}{*}{$c, d, t$} & 0.25 & -3.93 & -3.57 & -3.29 & -3.00 & -4.28 & -3.93 & -3.64 & -3.33 \\
\hline & 0.40 & -3.92 & -3.59 & -3.33 & -3.03 & -4.27 & -3.92 & -3.63 & -3.33 \\
\hline & 0.50 & -3.92 & -3.60 & -3.33 & -3.03 & -4.28 & -3.92 & -3.64 & -3.32 \\
\hline & 0.60 & -3.94 & -3.61 & -3.34 & -3.04 & -4.25 & -3.93 & -3.64 & -3.34 \\
\hline & 0.75 & -3.91 & -3.60 & -3.32 & -3.03 & -4.24 & -3.95 & -3.66 & -3.35 \\
\hline
\end{tabular}

The auxiliary regression can contain (no) constant $((\mathrm{n}) \mathrm{c})$, (no) seasonal dummies $((\mathrm{n}) \mathrm{d})$ and (no) trend $((\mathrm{n}) \mathrm{t})$. The DGP is $\left(1-B^{4}\right) y_{t}=\varepsilon_{t}$, with $\varepsilon_{t} \sim N(0,1)$, and the test is the one-sided $t$-test for $\pi_{1}$. Based on 25000 Monte Carlo replications for 20 years of observations. 
TABLE 15. Critical values for a test for a seasonal unit root in quarterly data with possible structural breaks at a fraction $\lambda$ of the data

\begin{tabular}{|c|c|c|c|c|c|c|c|c|c|}
\hline \multirow[b]{2}{*}{ Model } & \multirow[b]{2}{*}{$\lambda$} & \multicolumn{4}{|c|}{ Constant seasonal variation } & \multicolumn{4}{|c|}{ Varying seasonal variation } \\
\hline & & 0.01 & 0.025 & 0.05 & 0.10 & 0.01 & 0.025 & 0.05 & 0.10 \\
\hline \multirow[t]{5}{*}{$\mathrm{nc}, \mathrm{nd}, \mathrm{nt}$} & 0.25 & -3.23 & -2.86 & -2.55 & -2.19 & -3.21 & -2.85 & -2.52 & -2.18 \\
\hline & 0.40 & -3.07 & -2.75 & -2.47 & -2.13 & -3.05 & -2.74 & -2.46 & -2.12 \\
\hline & 0.50 & -3.11 & -2.76 & -2.43 & -2.07 & -3.09 & -2.73 & -2.41 & -2.06 \\
\hline & 0.60 & -3.01 & -2.65 & -2.33 & -1.96 & -3.00 & -2.63 & -2.30 & -1.94 \\
\hline & 0.75 & -2.91 & -2.53 & -2.20 & -1.83 & -2.89 & -2.52 & -2.18 & -1.82 \\
\hline \multirow[t]{5}{*}{$\mathrm{c}, \mathrm{nd}, \mathrm{nt}$} & 0.25 & -3.21 & -2.85 & -2.54 & -2.18 & -3.19 & -2.84 & -2.52 & -2.18 \\
\hline & 0.40 & -3.07 & -2.74 & -2.47 & -2.12 & -3.06 & -2.73 & -2.45 & -2.11 \\
\hline & 0.50 & -3.10 & -2.75 & -2.42 & -2.07 & -3.08 & -2.73 & -2.40 & -2.05 \\
\hline & 0.60 & -3.00 & -2.64 & -2.31 & -1.95 & -2.98 & -2.62 & -2.30 & -1.94 \\
\hline & 0.75 & -2.90 & -2.52 & -2.20 & -1.82 & -2.88 & -2.51 & -2.18 & -1.81 \\
\hline \multirow[t]{5}{*}{$\mathrm{c}, \mathrm{nd}, \mathrm{t}$} & 0.25 & -3.19 & -2.84 & -2.53 & -2.18 & -3.18 & -2.82 & -2.52 & -2.17 \\
\hline & 0.40 & -3.04 & -2.74 & -2.46 & -2.12 & -3.04 & -2.73 & -2.44 & -2.11 \\
\hline & 0.50 & -3.09 & -2.73 & -2.40 & -2.05 & -3.08 & -2.72 & -2.38 & -2.04 \\
\hline & 0.60 & -2.99 & -2.62 & -2.32 & -1.95 & -2.97 & -2.61 & -2.30 & -1.93 \\
\hline & 0.75 & -2.89 & -2.52 & -2.19 & -1.82 & -2.87 & -2.51 & -2.18 & -1.81 \\
\hline \multirow[t]{5}{*}{$\mathrm{c}, \mathrm{d}, \mathrm{nt}$} & 0.25 & -3.82 & -3.46 & -3.17 & -2.85 & -3.80 & -3.44 & -3.15 & -2.84 \\
\hline & 0.40 & -3.91 & -3.54 & -3.27 & -2.94 & -3.88 & -3.53 & -3.25 & -2.93 \\
\hline & 0.50 & -3.88 & -3.56 & -3.29 & -2.97 & -3.85 & -3.54 & -3.27 & -2.96 \\
\hline & 0.60 & -3.90 & -3.55 & -3.26 & -2.95 & -3.87 & -3.52 & -3.24 & -2.94 \\
\hline & 0.75 & -3.81 & -3.47 & -3.21 & -2.88 & -3.78 & -3.45 & -3.18 & -2.86 \\
\hline \multirow[t]{5}{*}{$c, d, t$} & 0.25 & -3.82 & -3.46 & -3.18 & -2.86 & -3.80 & -3.44 & -3.16 & -2.84 \\
\hline & 0.40 & -3.91 & -3.54 & -3.26 & -2.94 & -3.86 & -3.52 & -3.24 & -2.91 \\
\hline & 0.50 & -3.87 & -3.56 & -3.28 & -2.97 & -3.85 & -3.52 & -3.25 & -2.95 \\
\hline & 0.60 & -3.89 & -3.55 & -3.26 & -2.95 & -3.86 & -3.52 & -3.24 & -2.93 \\
\hline & 0.75 & -3.80 & -3.47 & -3.20 & -2.88 & -3.77 & -3.45 & -3.18 & -2.86 \\
\hline
\end{tabular}

The auxiliary regression can contain (no) constant $((\mathrm{n}) \mathrm{c})$, (no) seasonal dummies $((\mathrm{n}) \mathrm{d})$ and (no) trend ((n)t). The DGP is $\left(1-B^{4}\right) y_{t}=\varepsilon_{t}$, with $\varepsilon_{t} \sim N(0,1)$, and the test equations are equations (15) and (16), and the test is the one-sided $t$-test for $\pi_{2}$. Based on 25000 Monte Carlo replications for 20 years of observations.

filter for $y_{t}$ can be found via testing the significance of $\pi_{1}$ and $\pi_{2}$. Again, there are four possible outcomes. When both $\pi_{1}$ and $\pi_{2}$ are equal to zero, the $\Delta_{1} \Delta_{S}$ filter is selected. When neither is equal to zero, no differencing filter is needed. When $\pi_{1}=0$ and $\pi_{2} \neq 0$, one selects the $(1-B)$ filter and, in the other case, the $\left(1-B^{S}\right)$ filter is preferred. Obviously, this is the main distinction between the test of Osborn et al. and the approach of Hylleberg et al. because equation (13) does not consider seasonal unit roots separately.

In Table 12, we display the critical values of the one-sided $t$-statistics for $\pi_{1}$ and $\pi_{2}$, and the joint $F$-test for $\left\{\pi_{1}, \pi_{2}\right\}$, for quarterly and monthly time series for 10 , 20, 30 and 40 years of observations. The $\mu_{t}$ term in equation (14) contains a constant and $S-1$ seasonal dummies, which is the standard Osborn et al. case (nt, ndt). Furthermore, $\beta_{0}$ can be unequal to zero ( $\mathrm{t}, \mathrm{ndt}$ ) and $\beta_{i}$ for $i=0, \ldots, S-1$ can be unequal to zero $(t, d t)$.

An application of the auxiliary regression of equation (13) to our running example data on quarterly Dutch car sales in Table 13 indicates that $t\left(\pi_{1}\right)$ is always significant at the $1 \%$ level, independent of the model specification. This also holds 
TABLE 16. Critical values for a test for seasonal unit roots in quarterly data with possible structural breaks at a fraction $\lambda$ of the data

\begin{tabular}{|c|c|c|c|c|c|c|c|c|c|}
\hline \multirow[b]{2}{*}{ Model } & \multirow[b]{2}{*}{$\lambda$} & \multicolumn{4}{|c|}{ Constant seasonal variation } & \multicolumn{4}{|c|}{ Varying seasonal variation } \\
\hline & & 0.10 & 0.05 & 0.025 & 0.01 & 0.10 & 0.05 & 0.025 & 0.01 \\
\hline \multirow[t]{5}{*}{$\mathrm{nc}, \mathrm{nd}, \mathrm{nt}$} & 0.25 & 3.92 & 4.94 & 5.95 & 7.42 & 3.87 & 4.87 & 5.87 & 7.31 \\
\hline & 0.40 & 3.47 & 4.52 & 5.53 & 6.83 & 3.41 & 4.45 & 5.48 & 6.75 \\
\hline & 0.50 & 3.24 & 4.18 & 5.27 & 6.54 & 3.20 & 4.14 & 5.23 & 6.50 \\
\hline & 0.60 & 3.02 & 3.92 & 4.86 & 6.19 & 2.99 & 3.87 & 4.78 & 6.08 \\
\hline & 0.75 & 2.70 & 3.51 & 4.30 & 5.45 & 2.68 & 3.48 & 4.26 & 5.43 \\
\hline \multirow[t]{5}{*}{$\mathrm{c}, \mathrm{nd}, \mathrm{nt}$} & 0.25 & 3.88 & 4.87 & 5.86 & 7.36 & 3.83 & 4.83 & 5.79 & 7.19 \\
\hline & 0.40 & 3.42 & 4.45 & 5.46 & 6.73 & 3.38 & 4.38 & 5.41 & 6.68 \\
\hline & 0.50 & 3.20 & 4.14 & 5.18 & 6.49 & 3.16 & 4.09 & 5.13 & 6.39 \\
\hline & 0.60 & 2.96 & 3.86 & 4.78 & 6.08 & 2.92 & 3.81 & 4.74 & 5.97 \\
\hline & 0.75 & 2.66 & 3.46 & 4.24 & 5.43 & 2.62 & 3.42 & 4.21 & 5.33 \\
\hline \multirow[t]{5}{*}{$\mathrm{c}, \mathrm{nd}, \mathrm{t}$} & 0.25 & 3.84 & 4.83 & 5.76 & 7.23 & 3.78 & 4.80 & 5.72 & 7.13 \\
\hline & 0.40 & 3.38 & 4.39 & 5.39 & 6.68 & 3.33 & 4.34 & 5.37 & 6.62 \\
\hline & 0.50 & 3.14 & 4.10 & 5.13 & 6.36 & 3.11 & 4.06 & 5.10 & 6.28 \\
\hline & 0.60 & 2.91 & 3.82 & 4.72 & 6.00 & 2.89 & 3.78 & 4.67 & 5.89 \\
\hline & 0.75 & 2.63 & 3.40 & 4.19 & 5.31 & 2.59 & 3.36 & 4.13 & 5.20 \\
\hline \multirow[t]{5}{*}{$\mathrm{c}, \mathrm{d}, \mathrm{nt}$} & 0.25 & 7.11 & 8.43 & 9.74 & 11.42 & 7.02 & 8.28 & 9.63 & 11.30 \\
\hline & 0.40 & 7.61 & 8.93 & 10.27 & 11.83 & 7.55 & 8.85 & 10.13 & 11.66 \\
\hline & 0.50 & 7.76 & 9.16 & 10.48 & 12.01 & 7.69 & 9.09 & 10.34 & 11.91 \\
\hline & 0.60 & 7.63 & 8.99 & 10.32 & 12.02 & 7.55 & 8.88 & 10.23 & 11.89 \\
\hline & 0.75 & 7.04 & 8.38 & 9.70 & 11.35 & 6.97 & 8.28 & 9.61 & 11.30 \\
\hline \multirow[t]{5}{*}{$c, d, t$} & 0.25 & 7.05 & 8.36 & 9.69 & 11.38 & 6.97 & 8.28 & 9.57 & 11.22 \\
\hline & 0.40 & 7.58 & 8.90 & 10.18 & 11.76 & 7.47 & 8.78 & 10.07 & 11.62 \\
\hline & 0.50 & 7.74 & 9.14 & 10.44 & 11.85 & 7.63 & 9.01 & 10.30 & 11.76 \\
\hline & 0.60 & 7.60 & 8.92 & 10.27 & 12.04 & 7.49 & 8.80 & 10.15 & 11.85 \\
\hline & 0.75 & 7.02 & 8.36 & 9.66 & 11.26 & 6.93 & 8.26 & 9.51 & 11.18 \\
\hline
\end{tabular}

The auxiliary regression can contain (no) constant $((\mathrm{n}) \mathrm{c})$, (no) seasonal dummies $((\mathrm{n}) \mathrm{d})$ and (no) trend ((n)t). The DGP is $\left(1-B^{4}\right) y_{t}=\varepsilon_{t}$, with $\varepsilon_{t} \sim N(0,1)$, and the test equations are equations (15) and (16), and the test is the $F$-test for $\pi_{3}$ and $\pi_{4}$. Based on 25000 Monte Carlo replications for 20 years of observations.

for the $F\left(\pi_{1}, \pi_{2}\right)$-test. The $t\left(\pi_{2}\right)$-test outcomes suggest that, at most, the $\Delta_{4}$ filter is needed to transform the car sales to stationarity. Hence, this series does not have two unit roots at the zero frequency.

\section{Seasonal unit roots and structural breaks}

In this section, we display critical values of test statistics of the Hylleberg et al. type, in the case where the auxiliary regression contains additional seasonal dummies which become effective only at time $\tau$, where $\tau=\lambda n$, with $0<\lambda<1$. The motivation for this extension is to allow for the possibility of a known structural break in the seasonal constants. Following the seminal paper by Perron (1989), it is now well understood that neglecting structural breaks or mean shifts biases unit root test statistics towards non-rejection. In the case of shifts in the seasonal means, it may then occur that one finds too many seasonal unit roots. In this paper, we only consider the case of one known break, which corresponds to the first season 
TABLE 17. Critical values for a test for seasonal unit roots in quarterly data with possible structural breaks at a fraction $\lambda$ of the data

\begin{tabular}{|c|c|c|c|c|c|c|c|c|c|}
\hline \multirow[b]{2}{*}{ Model } & \multirow[b]{2}{*}{$\lambda$} & \multicolumn{4}{|c|}{ Constant seasonal variation } & \multicolumn{4}{|c|}{ Varying seasonal variation } \\
\hline & & 0.10 & 0.05 & 0.025 & 0.01 & 0.10 & 0.05 & 0.025 & 0.01 \\
\hline \multirow[t]{5}{*}{$\mathrm{nc}, \mathrm{nd}, \mathrm{nt}$} & 0.25 & 3.62 & 4.44 & 5.27 & 6.31 & 3.56 & 4.39 & 5.23 & 6.28 \\
\hline & 0.40 & 3.31 & 4.08 & 4.86 & 5.88 & 3.27 & 4.02 & 4.82 & 5.81 \\
\hline & 0.50 & 3.09 & 3.85 & 4.62 & 5.67 & 3.05 & 3.81 & 4.56 & 5.59 \\
\hline & 0.60 & 2.88 & 3.61 & 4.38 & 5.27 & 2.84 & 3.57 & 4.32 & 5.23 \\
\hline & 0.75 & 2.61 & 3.24 & 3.96 & 4.80 & 2.58 & 3.20 & 3.91 & 4.71 \\
\hline \multirow[t]{5}{*}{$\mathrm{c}, \mathrm{nd}, \mathrm{nt}$} & 0.25 & 3.58 & 4.40 & 5.22 & 6.24 & 3.53 & 4.34 & 5.16 & 6.24 \\
\hline & 0.40 & 3.28 & 4.01 & 4.79 & 5.80 & 3.24 & 3.98 & 4.74 & 5.74 \\
\hline & 0.50 & 3.05 & 3.81 & 4.56 & 5.62 & 3.02 & 3.77 & 4.52 & 5.56 \\
\hline & 0.60 & 2.84 & 3.57 & 4.30 & 5.25 & 2.81 & 3.52 & 4.23 & 5.16 \\
\hline & 0.75 & 2.58 & 3.21 & 3.94 & 4.72 & 2.55 & 3.17 & 3.87 & 4.65 \\
\hline \multirow[t]{5}{*}{$\mathrm{c}, \mathrm{nd}, \mathrm{t}$} & 0.25 & 3.55 & 4.37 & 5.15 & 6.21 & 3.52 & 4.30 & 5.08 & 6.12 \\
\hline & 0.40 & 3.24 & 3.98 & 4.75 & 5.77 & 3.20 & 3.94 & 4.71 & 5.69 \\
\hline & 0.50 & 3.03 & 3.79 & 4.53 & 5.58 & 2.99 & 3.75 & 4.48 & 5.49 \\
\hline & 0.60 & 2.81 & 3.51 & 4.25 & 5.20 & 2.78 & 3.48 & 4.18 & 5.14 \\
\hline & 0.75 & 2.54 & 3.17 & 3.86 & 4.66 & 2.51 & 3.13 & 3.79 & 4.59 \\
\hline \multirow[t]{5}{*}{$\mathrm{c}, \mathrm{d}, \mathrm{nt}$} & 0.25 & 6.67 & 7.82 & 8.90 & 10.22 & 6.59 & 7.71 & 8.80 & 10.11 \\
\hline & 0.40 & 7.21 & 8.33 & 9.32 & 10.70 & 7.13 & 8.27 & 9.23 & 10.61 \\
\hline & 0.50 & 7.35 & 8.52 & 9.53 & 11.00 & 7.27 & 8.45 & 9.47 & 10.88 \\
\hline & 0.60 & 7.20 & 8.39 & 9.42 & 10.76 & 7.13 & 8.31 & 9.34 & 10.67 \\
\hline & 0.75 & 6.68 & 7.81 & 8.88 & 10.21 & 6.61 & 7.70 & 8.74 & 10.13 \\
\hline \multirow[t]{5}{*}{$c, d, t$} & 0.25 & 6.65 & 7.80 & 8.84 & 10.17 & 6.59 & 7.70 & 8.74 & 10.06 \\
\hline & 0.40 & 7.19 & 8.34 & 9.32 & 10.63 & 7.08 & 8.22 & 9.20 & 10.51 \\
\hline & 0.50 & 7.33 & 8.51 & 9.55 & 10.97 & 7.22 & 8.37 & 9.42 & 10.78 \\
\hline & 0.60 & 7.20 & 8.38 & 9.41 & 10.72 & 7.09 & 8.24 & 9.28 & 10.59 \\
\hline & 0.75 & 6.68 & 7.76 & 8.86 & 10.22 & 6.60 & 7.67 & 8.74 & 10.08 \\
\hline
\end{tabular}

The auxiliary regression can contain (no) constant $((\mathrm{n}) \mathrm{c})$, (no) seasonal dummies $((\mathrm{n}) \mathrm{d})$ and (no) trend $((\mathrm{n}) \mathrm{t})$. The DGP is $\left(1-B^{4}\right) y_{t}=\varepsilon_{t}$, with $\varepsilon_{t} \sim N(0,1)$, the test equations are equations (15) and (16), and the test is the $F$-test for $\pi_{2}, \pi_{3}$ and $\pi_{4}$. Based on 25000 Monte Carlo replications for 20 years of observations.

in a year. This means that $\tau$ corresponds to the first quarter or month. Furthermore, to save space, we limit our discussion to $S=4$.

We consider two possible modifications of the Hylleberg et al. test in equation (7). The first modification is to add seasonal dummy variables such that all unit root tests are affected, i.e. equation (7) becomes

$$
\phi(B) y_{4, t}=\mu_{t}+\pi_{1} y_{1, t-1}+\pi_{2} y_{2, t-1}+\pi_{3} y_{3, t-2}+\pi_{4} y_{3, t-1}+\mu_{t}^{\star}\left[I_{t \geqslant \tau}\right]+\varepsilon_{t}
$$

where

$$
\mu_{t}^{\star}=\sum_{s=1}^{4} \alpha_{s}^{\star} D_{s t}
$$

This regression can be called the 'varying seasonal variation' model because all seasons may change as a result of $\alpha_{s}^{\star}$. Hence, the total seasonal variation may change if only one of $\alpha_{s}^{\star}$ terms is unequal to zero, for example. This possibility will affect the distribution of all test statistics of the Hylleberg et al. type.

If one wishes to restrict the seasonal variation to be equal before and after $\tau$, 
TABLE 18. Critical values for a test for all unit roots in quarterly data with possible structural breaks at a fraction $\lambda$ of the data

\begin{tabular}{|c|c|c|c|c|c|c|c|c|c|}
\hline \multirow[b]{2}{*}{ Model } & \multirow[b]{2}{*}{$\lambda$} & \multicolumn{4}{|c|}{ Constant seasonal variation } & \multicolumn{4}{|c|}{ Varying seasonal variation } \\
\hline & & 0.10 & 0.05 & 0.025 & 0.01 & 0.10 & 0.05 & 0.025 & 0.01 \\
\hline \multirow[t]{5}{*}{$\mathrm{nc}, \mathrm{nd}, \mathrm{nt}$} & 0.25 & 3.14 & 3.82 & 4.43 & 5.26 & 3.44 & 4.14 & 4.87 & 5.74 \\
\hline & 0.40 & 2.87 & 3.49 & 4.11 & 4.88 & 3.13 & 3.81 & 4.45 & 5.36 \\
\hline & 0.50 & 2.74 & 3.33 & 3.95 & 4.75 & 2.94 & 3.59 & 4.23 & 5.04 \\
\hline & 0.60 & 2.58 & 3.18 & 3.75 & 4.52 & 2.77 & 3.41 & 3.99 & 4.80 \\
\hline & 0.75 & 2.37 & 2.92 & 3.45 & 4.09 & 2.48 & 3.05 & 3.59 & 4.33 \\
\hline \multirow[t]{5}{*}{$\mathrm{c}, \mathrm{nd}, \mathrm{nt}$} & 0.25 & 3.75 & 4.47 & 5.12 & 6.01 & 4.15 & 4.89 & 5.64 & 6.61 \\
\hline & 0.40 & 3.52 & 4.19 & 4.84 & 5.72 & 4.03 & 4.76 & 5.51 & 6.49 \\
\hline & 0.50 & 3.36 & 4.03 & 4.72 & 5.51 & 3.94 & 4.65 & 5.33 & 6.25 \\
\hline & 0.60 & 3.19 & 3.84 & 4.45 & 5.30 & 3.71 & 4.41 & 5.10 & 5.95 \\
\hline & 0.75 & 3.02 & 3.61 & 4.23 & 5.03 & 3.42 & 4.09 & 4.74 & 5.56 \\
\hline \multirow[t]{5}{*}{$\mathrm{c}, \mathrm{nd}, \mathrm{t}$} & 0.25 & 4.45 & 5.18 & 5.92 & 6.86 & 4.89 & 5.68 & 6.49 & 7.44 \\
\hline & 0.40 & 4.18 & 4.92 & 5.61 & 6.53 & 4.58 & 5.37 & 6.18 & 7.17 \\
\hline & 0.50 & 4.07 & 4.78 & 5.48 & 6.37 & 4.47 & 5.22 & 5.94 & 6.96 \\
\hline & 0.60 & 3.90 & 4.62 & 5.29 & 6.11 & 4.34 & 5.07 & 5.77 & 6.69 \\
\hline & 0.75 & 3.71 & 4.38 & 5.01 & 5.77 & 4.20 & 4.90 & 5.58 & 6.44 \\
\hline \multirow[t]{5}{*}{$\mathrm{c}, \mathrm{d}, \mathrm{nt}$} & 0.25 & 6.02 & 6.97 & 7.83 & 8.96 & 6.38 & 7.36 & 8.28 & 9.50 \\
\hline & 0.40 & 6.44 & 7.38 & 8.28 & 9.37 & 6.93 & 7.95 & 8.91 & 10.13 \\
\hline & 0.50 & 6.55 & 7.55 & 8.46 & 9.64 & 7.12 & 8.15 & 9.05 & 10.22 \\
\hline & 0.60 & 6.42 & 7.37 & 8.29 & 9.45 & 6.89 & 7.90 & 8.87 & 10.03 \\
\hline & 0.75 & 6.06 & 6.97 & 7.86 & 8.99 & 6.40 & 7.36 & 8.31 & 9.46 \\
\hline \multirow[t]{5}{*}{$c, d, t$} & 0.25 & 6.69 & 7.68 & 8.63 & 9.85 & 7.12 & 8.19 & 9.10 & 10.45 \\
\hline & 0.40 & 7.16 & 8.13 & 9.07 & 10.31 & 7.50 & 8.55 & 9.54 & 10.79 \\
\hline & 0.50 & 7.28 & 8.30 & 9.24 & 10.51 & 7.61 & 8.66 & 9.68 & 10.96 \\
\hline & 0.60 & 7.17 & 8.20 & 9.11 & 10.27 & 7.49 & 8.58 & 9.48 & 10.74 \\
\hline & 0.75 & 6.73 & 7.69 & 8.62 & 9.81 & 7.15 & 8.15 & 9.11 & 10.48 \\
\hline
\end{tabular}

The auxiliary regression can contain (no) constant $((\mathrm{n}) \mathrm{c})$, (no) seasonal dummies $((\mathrm{n}) \mathrm{d})$ and (no) trend $((\mathrm{n}) \mathrm{t})$. The DGP is $\left(1-B^{4}\right) y_{t}=\varepsilon_{t}$, with $\varepsilon_{t} \sim N(0,1)$, the test equations are equations (15) and (16), and the test is the $F$-test for $\pi_{1}, \pi_{2}, \pi_{3}$ and $\pi_{4}$. Based on 25000 Monte Carlo replications for 20 years of observations.

then one can estimate the parameters in equation (15) with

$$
\mu_{t}^{\star}=\sum_{s=1}^{3} \alpha_{s}^{\star \star} D_{s t}^{\star}
$$

where the $D_{s t}^{\star}$ terms are defined by $D_{s t}-D_{s-1, t}$. In this case, it is clear that, when a certain seasonal mean changes, this shift carries over to one of the other quarters. The total seasonal variation remains constant and the test for a unit root at the non-seasonal frequency should not be affected.

In Tables 14-18, we report the Hylleberg et al. test statistics $t\left(\pi_{1}\right), t\left(\pi_{2}\right), F\left(\pi_{3}, \pi_{4}\right)$, $F\left(\pi_{2}, \pi_{3}, \pi_{4}\right)$ and $F\left(\pi_{1}, \pi_{2}, \pi_{3}, \pi_{4}\right)$ for 20 years of observations and for $\lambda$ equal to $0.25,0.4,0.5,0.6$ and 0.75 . Formal asymptotics for these tests are yet to be derived.

To illustrate the effect of structural mean shifts, we consider again the quarterly car sales data. The measurement system for new cars in the Netherlands changed in September 1975. This may have affected the seasonal pattern. In our application, we set $\tau=1976.1$, and we consider the case where the regression contains a constant, three seasonal dummies and a trend. Some experimentation indicates 
that no lags of $\Delta_{4} y_{t}$ have to be included in equation (15). We report the results for the varying seasonal variation case, and mention that similar results are obtained for the constant seasonal variation case. The test values are as follows:

$$
\begin{aligned}
t\left(\pi_{1}\right) & =-2.101 \\
t\left(\pi_{2}\right) & =-5.420 \star \star \star \\
F\left(\pi_{3}, \pi_{4}\right) & =21.779 \star \star \star \\
F\left(\pi_{2}, \pi_{3}, \pi_{4}\right) & =24.203 \star \star \star \\
F\left(\pi_{1}, \pi_{2}, \pi_{3}, \pi_{4}\right) & =19.640^{\star \star \star}
\end{aligned}
$$

Here, ${ }^{\star \star}$ indicates significance at the $1 \%$ level. These results indicate that evidence for seasonal unit roots disappears once we allow for deterministic seasonal mean shifts in Dutch new car sales.

\section{Acknowledgements}

The first author thanks the Royal Netherlands Academy of Arts and Sciences for its financial support. The authors also thank a referee for several helpful comments.

\section{REFERENCES}

Abraham, B. \& Box, G. E. P. (1978) Deterministic and forecast-adaptive time-dependent models, Applied Statistics, 27, pp. 120-130.

Banerjee, A., Dolado, J., Galbraith, J. W. \& Hendry, D. F. (1993) Co-integration Error Correction, and the Econometric Analysis of Non-stationary Data (Oxford, Oxford University Press).

BeAulieu, J. J. \& Miron, J. A. (1993) Seasonal unit roots in aggregate US data, fournal of Econometrics, 55, pp. 305-328.

DiCKey, D. A. \& FUller, W. A. (1979) Distribution of estimators for autoregressive time series with a unit root, fournal of the American Statistical Association, 74, pp. 427-431.

FRANSES, P. H. (1990) Testing for seasonal unit roots in monthly data, Econometric Institute Report 9032 (Rotterdam, Erasmus University Rotterdam).

Franses, P. H. (1991a) Model Selection and Seasonality in Time Series (Rotterdam, Tinbergen Institute Rotterdam, Thesis Publishers).

FRANSES, P. H. (1991b) Seasonality, nonstationarity and the forecasting of monthly time series, International fournal of Forecasting, 7, pp. 199-208.

Franses, P. H. \& Koehler, A. B. (1996) Model selection strategies for time series with increasing seasonal variation, (revised version of) Econometric Institute Report 9308 (Rotterdam, Erasmus University Rotterdam).

Ghysels, E., LEE, H. S. \& NoH, J., (1994) Testing for unit roots in seasonal time series, fournal of Econometrics, 62, pp. 415-442.

Hylleberg, S., Engle, R. F., Granger, C. W. J. \& Yoo, B. S. (1990) Seasonal integration and cointegration, fournal of Econometrics, 44, pp. 215-238.

Osborn, D. R., Chui, A. P. L., Smith, J. P. \& Birchenhall, C. R. (1988), Seasonality and the order of integration for consumption, Oxford Bulletin of Economics and Statistics, 50, pp. 361-377.

Perron, P. (1989) The great crash, the oil price shock, and the unit root hypothesis, Econometrica, 57, pp. 1361-1401. 
Appendix: Quarterly new car sales in the Netherlands, 1960.1-1988.4

\begin{tabular}{|c|c|c|c|c|}
\hline Year & Q1 & Q2 & Q3 & Q4 \\
\hline 1960 & 23846 & 29504 & 22623 & 20988 \\
\hline 1961 & 29963 & 34769 & 26340 & 24230 \\
\hline 1962 & 34894 & 41911 & 32412 & 29220 \\
\hline 1963 & 33824 & 53958 & 47675 & 37061 \\
\hline 1964 & 52603 & 71087 & 46464 & 41676 \\
\hline 1965 & 59711 & 77056 & 48355 & 79694 \\
\hline 1966 & 43953 & 68618 & 47877 & 46222 \\
\hline 1967 & 62158 & 72951 & 55096 & 50519 \\
\hline 1968 & 77281 & 116980 & 71154 & 69260 \\
\hline 1969 & 82898 & 117954 & 70584 & 78127 \\
\hline 1970 & 100435 & 129313 & 98247 & 104236 \\
\hline 1971 & 104782 & 135010 & 84390 & 78526 \\
\hline 1972 & 107598 & 132847 & 93175 & 98463 \\
\hline 1973 & 123431 & 129362 & 86780 & 90358 \\
\hline 1974 & 83282 & 121115 & 100700 & 99845 \\
\hline 1975 & 120480 & 116412 & 89830 & 123498 \\
\hline 1976 & 120262 & 126949 & 157534 & 103606 \\
\hline 1977 & 155151 & 166219 & 128461 & 102101 \\
\hline 1978 & 160556 & 178535 & 112428 & 133067 \\
\hline 1979 & 179584 & 168966 & 104146 & 99907 \\
\hline 1980 & 159943 & 126689 & 87496 & 70705 \\
\hline 1981 & 131386 & 117853 & 78434 & 58810 \\
\hline 1982 & 121887 & 125273 & 82710 & 73233 \\
\hline 1983 & 147909 & 140393 & 94090 & 73962 \\
\hline 1984 & 161818 & 136434 & 86564 & 76575 \\
\hline 1985 & 159898 & 146962 & 103403 & 85457 \\
\hline 1986 & 177851 & 170822 & 121655 & 88507 \\
\hline 1987 & 188897 & 167421 & 111099 & 86886 \\
\hline 1988 & 175782 & 136175 & 97059 & 71633 \\
\hline
\end{tabular}



Copyright of Journal of Applied Statistics is the property of Carfax Publishing Company and its content may not be copied or emailed to multiple sites or posted to a listserv without the copyright holder's express written permission. However, users may print, download, or email articles for individual use. 